ANNE M. HYLAND

Rhetorical Closure in the First Movement of Schubert's
Quartet in C major, D. 46: A Dialogue with Deformation

\title{
The Methodological Problem
}

[W] hen it comes to Schubert's music we speak of 'landscape'.

(Adorno 2005, p. 7)

Despite the prevalence of spatial metaphors in current musicological discourse and music analysis (symptomatic in part of the ascendancy of neo-Riemannian models of tonal pitch space), the idea that music consists of directed, teleological motion remains orthodox, even if it no longer takes centre stage. ${ }^{1}$ This is most clearly illustrated in the metaphor of the musical landscape, originating with Adorno's 1928 essay on Schubert's music, cited above, and revived and given nuance by Mark Johnson and Steve Larson (2003) in the field of metaphor theory. The inherent duality of the metaphor of musical space, which Michael Spitzer has fittingly termed 'pathways through a landscape' (2003, p. 103), is understood as incorporating elements of the temporal or progressive aspects of music into the metaphorical domain of the spatial ones. Their theoretical relationship is therefore reciprocal and permeable.

Musical time and space do not, however, make methodologically easy bedfellows. Even if we have no quarrel with the once-contended assertion that 'musical space is ... inseparable from musical time, just as musical time is inseparable from musical space' (Morgan 1980, p. 529) and are in agreement that 'we ought to treat their relationship as one of complex interaction, interdependence, and interpenetration' (Mitchell 1980, p. 544), the challenge of how best to carry this out in analytical practice remains significant. David Epstein's scathing remarks on this question are worth considering:

\footnotetext{
Analysis imposes a disparity of treatment, indeed of perception, between the spatial and the temporal in music, a disparity supported by both the graphology and the terminology of analysis itself. For analysis is largely static - dividing, studying in terms of component parts. Its terminology is compatible with this and is likewise oriented toward isolable study. (Epstein 1979, p. 195)
}

Although Epstein's observations may seem pessimistic (and considerably outmoded) by contemporary standards, their first appearance in 1979 foregrounded the need for a taxonomy which facilitated dialogue, in the most general sense, between the spatial and temporal dimensions of music. By calling attention to 
the perceived incompatibility between the spatially orientated vocabulary and conceptualisations employed in analysis on one hand, and the temporal and specifically directional nature of tonal music on the other, Epstein, among others, took a decisive step towards their methodological rapprochement. ${ }^{2}$

The publication in 2006 of James Hepokoski and Warren Darcy's highly anticipated Elements of Sonata Theory marked a defining moment in the history of this debate. Founded upon a conception of sonata form in which individual movements are understood as entering into dialogue with a set of generic norms or conventions, sonata theory's emphasis on communication and exchange seemed to offer a suitable forum for the coexistence of musical time and space. Indeed, the dialogical metaphor extends to the philosophical essence of the theory itself. Despite the authors' reliance on metaphors of formal space ('action-zones', 'thematic modules', 'trimodular blocks', and so forth), their concept of sonata form remains decidedly teleological, concerned with 'the recognition and interpretation of expressive/dramatic trajectories toward generically obligatory cadences' (Hepokoski and Darcy 2006, p. 13). ${ }^{3}$ These goal-directed trajectories make up sonata theory's fundamental premise that an exposition generates material which moves towards a point of essential expositional closure (EEC) and, equally, that a whole movement tends towards essential structural closure (ESC) - defined as 'the goal toward which the entire sonatatrajectory has been aimed' (ibid., 2006, p. 232). They exist, however, only in relation to the spatial elements of the form (the zones, modules and blocks mentioned above), which are in turn identified by the presence of fixed cadential points. These cadences punctuate (or 'interrupt') the form and provide the defining moments of each sonata space - an aspect of the theory highlighted by Michael Spitzer's "“punctuation model"' (Spitzer 2007, p. 151). Thus, for sonata theory, the ultimate telos of a movement's dynamic trajectory (the ESC) is, we might say, housed within a specific sonata space, namely the secondarytheme zone $(\mathrm{S})$ of the recapitulation - a temporal goal manifesting itself within a spatial model.

Notwithstanding the merits of this approach, inherent difficulties are revealed when sonata theory is employed analytically, difficulties which result from subordinating a temporal process to the principles of a prefabricated, spatially defined mould. ${ }^{4}$ That is to say, when put into practice, sonata theory seems more akin to a set of criteria to be met or engaged with than a taxonomy by which to classify or interpret the individual workings out of a specific movement. This article investigates two concomitant issues: sonata theory's inattention to parametric non-congruence in its treatment of the articulation of closure, and its tendency towards what I term the functional alienation of parageneric zones. ${ }^{5}$ The first of these occupies the greater share of the analysis, since it encapsulates the central issue addressed by this essay. Before exploring the analytical ramifications of this in the first movement of Schubert's String Quartet in C major, D. 46, however, I wish to clarify my use of the term rhetorical closure and its interaction with the tenets of sonata theory via a brief examination of tonal and 
rotational principles, with the aim of suggesting alternative routes towards charting the Schubertian 'landscape'.

\section{The Parameters of Closure in Theory and Analytical Practice}

Parameters ... need not coincide to bring about closure.

(Anson-Cartwright 2007, p. 1)

The concept of closure, as explored by Mark Anson-Cartwright (2007), is a two-pronged phenomenon incorporating both syntactic and non-syntactic (or non-semantic and semantic) elements, the former commonly being taken as paramount:

The only concept or type of closure with ... strong and obvious empirical support is tonal closure; perhaps for that reason, most descriptions and models of closure privilege tonal closure. This fact may help explain why other aspects (or 'secondary parameters') of closure in tonal music - form, rhythm, motivic development, texture, orchestration, and dynamics, to name a few - tend to be neglected, or subordinated to tonal factors. (Anson-Cartwright 2007, p. 2)

The distinction I make between tonal and rhetorical closure stems from the underlying principle outlined by Anson-Cartwright, although my analysis seeks to redress the universal bias he perceives towards tonal closure. My use of the term rhetorical in this manner makes specific reference to V. Kofi Agawu's work on structural highpoints (1982 and 1984) and closure (1987), in which he distinguishes between structural parameters (those possessing hierarchical authority by virtue of being functionally indispensable) and rhetorical parameters (those which 'serve to articulate the formal process of the work in question' [Agawu 1982, p. 5; my emphasis]). Thus, for Agawu, rhetorical elements are not consistent from one work to another, although they are nonetheless drawn from the same pool of secondary parameters mentioned by Anson-Cartwright. Within this definition, the cadence fulfils a 'syntactical obligation, [but] does not carry sufficient rhetorical weight to provide an effective balance for the period as a whole' (Agawu 1991, p. 81). Rhetorical closure, for the present purposes, constitutes those signals of a work's finality or closure which are not tonal in nature.

The attainment of closure is, of course, fundamental to sonata theory's goal-directed view of sonata form, as is indicated by the theory's emphasis on tonal closure and phrase endings as defining features of sonata space (recall Spitzer's 'punctuation model'). In their concept of sonata form, Hepokoski and Darcy clearly separate the roles played by tonal and rhetorical elements: 'Tonal form is to be distinguished from rhetorical form, which includes personalized factors of design and ad hoc expression: modular and textual layout, selection and arrangement of musical topics, varieties of structural punctuation, and so on' (2006, p. 23). In other words, although tonal form is 'generally the same in all 
sonatas' (ibid.), rhetorical form, echoing Agawu's definition, constitutes the individual shape of a particular movement.

Anson-Cartwright's claim that rhetorical elements 'tend to be neglected, or subordinated to tonal factors', in the articulation of form is both reinforced and challenged by sonata theory. On one level, tonal form is presented as hierarchically superior to rhetorical form in that it is indispensable to the existence of $S$ in expositional space. The authors' bold (and often-quoted) assertion that '[i]f there is no medial caesura, there is no secondary theme' (Hepokoski and Darcy 2006, p. 52) indicates the dominance in their theory of tonal - or, more accurately, cadential - concerns. This is so because although a medial caesura (MC) is presented as a rhetorical device, one constituting a 'brief, rhetorically reinforced break or gap that serves to divide an exposition into two parts', its 'execution ... [is] "built around" a half-cadence effect or "dominant-arrival effect" in either the tonic or the dominant key' (ibid., p. 24). ${ }^{6}$ The indispensability of this cadential support to the MC is most obvious in its absence - that is, in cases where the MC is articulated rhetorically as an interruption on the musical surface but the lack of an expected cadence reinforcing it renders the appearance of $S$ unachievable. The ramifications of this are far-reaching: the presence of the tonally executed $\mathrm{MC}$ is vital not only to $\mathrm{S}$, but also to the movement in toto, since ' $[w]$ hat happens in S makes a sonata a sonata' (ibid., p. 117).

On the contrary, in sonata theory tonality is allegedly of subsidiary importance - or, rather, of no importance whatsoever - in identifying the commencement of the recapitulatory rotation: ' $[\mathrm{w}]$ ithin a sonata, tonality is irrelevant to the task of identifying the rotational principle' (Hepokoski and Darcy 2006, p. 612). ${ }^{7}$ The 'rotational principle' is concerned with cycles of thematic return, which are laid out in the exposition (the 'referential rotation' [ibid., p. 23]) and revisited in sequence (or purposely not) in the ensuing sections of the development, recapitulation and coda. The complete irrelevance of tonality to the rotational principle is clear: 'Rotation is what we call a rhetorical principle rather than a tonal one: it is governed by the expectation of a temporal presentation-sequence of thematic-modular elements, not by harmonic procedures' (ibid., p. 612). The authors' 'resolutely rotational perspective' (ibid., p. 277) is nowhere more in evidence than when outlining the 'inappropriateness of the term "recapitulation"' (ibid., p. 353) to the Type 2 sonata. While recapitulatory rotations in non-tonic keys are permitted within Type 3 sonatas (because of the thematic parallel with the exposition), the opposite situation of a return of $S$ in the tonic key is apparently indicative of a Type 2 sonata, in which the second rotation begins with a continuation of developmental space and the return of the tonic acts as only a 'tonal resolution' (ibid., p. 353) occurring halfway through this second rotation. (Schubert's propensity for writing non-tonic recapitulations of his main themes obviously complicates this issue and will be explored in the ensuing analysis.) Considering the treatment of $S$ in the exposition, in particular its dependence on the articulation of tonality, it is difficult not to be confused by Hepokoski and Darcy's remark that 
it is inappropriate to claim that the 'recapitulation' in a Type 2 sonata 'begins with S'. Such an assertion, still commonly encountered, is one of several unfortunate consequences arising from the eagerness in the mid-twentieth century to define a sonata only in tonal terms, pushing to the side important considerations of thematic function and arrangement. (2006, p. 354; my emphasis)

Given that the authors offer no explanation for this shift in perspective, it is not very surprising that their 'rotational principle' has been met with such suspicion, for instance by Paul Wingfield, who compares its acceptance to 'an act of quasi-religious faith' (Wingfield 2008, p. 149) and submits the fair question: '[W] hat are readers [analysts] to make of the fact that here [in the exposition of Mozart's Quartet, K. 421/i] tonal concerns seem to be paramount, whereas on other occasions - for instance at times when recapitulations are posited to begin in non-tonic keys ... - thematic elements are privileged?' (ibid., p. 167).

None of this implies a fundamental contradiction in sonata theory, especially if we accept and maintain as discrete its tonal and rotational trajectories; it does, however, highlight the difficulties which arise when applying the theory in practice. Hepokoski and Darcy's oddly capricious treatment of 'tonal' and 'rhetorical' form in sonata theory complicates the relationship between the spatial and temporal and muddies its interpretation. This is especially true of movements in which tonal and rhetorical plots do not, as Hepokoski and Darcy have it, 'unfold simultaneously, intertwined with each other in mutually reinforcing ways' (2006, p. 18), but seem instead to undercut or contradict each other.

Most pressing in the articulation of form are moments where one parameter is suggestive of closure (and thus the commencement of a new zone) but one or more of the others are not - a practice frequently encountered in Schubert's instrumental music. As noted above, when such instances do arise in an expositional rotation (and this is not infrequent), sonata theory's 'default' is to grant prominence to tonality in the guise of cadential articulation, thereby ignoring the effects of parametric non-congruence. ' 'Cadence', as William Caplin rightly maintains, 'creates musical closure, but not all closure in music is cadential' (Caplin 2004, p. 56). A multivalent approach to analysis, which '[i]nsofar as is possible ... proceed[s initially] one domain at a time, with little attention to what happens in the other domains and without preconceptions as to the overall form' (Webster 1992, p. 28) and which views form as the combination of these domains, is therefore more alert to the interaction and conflict of individual parameters than is sonata theory and facilitates investigation into the significance of their non-congruence. For this reason I have adopted a largely multivalent perspective in the ensuing analysis.

The first movement of Schubert's String Quartet in C major, D. 46, a relatively early (1813) and regrettably much-neglected work, offers a particularly apt case study of closure, for its tonal and rhetorical plans chart two distinct trajectories, calling into question the network of criteria and defaults employed by sonata theory in defining sonata spaces. ${ }^{9}$ The movement presents two struc- 
turally significant instances of parametric non-congruence. The first of these relates to the identification of $S$ in the exposition, which, as suggested above, is complicated by the fact that the expected tonal conflict between tonic and dominant does not arise, despite the introduction of new thematic material. In order to explicate the problem, I shall present two contrasting analyses of the exposition, both employing sonata-theoretical procedures, although to different ends: the first offers a tonally orientated interpretation along sonata-theoretical lines, while the second is more responsive to rhetorical, and specifically thematic, considerations. These two readings call into question the usefulness in this instance of the terms continuous exposition and two-part exposition. The movement's second formal peculiarity occurs at the point of recapitulation, which begins over an active ${ }_{4}^{6}$ chord. ${ }^{10}$ In this respect, D. 46/i is aberrant or 'nonnormative' in sonata theory's terms; but because the recapitulation obeys the 'rotational principle', it must be considered a Type 3 sonata. ${ }^{11}$ The analysis explores the ramifications of this dominant recapitulation for the movement as a whole. Additionally, the pivotal role played by the opening gesture of the adagio introduction (a descending chromatic tetrachord) in articulating structure will be considered alongside the recapitulation. Ultimately, I seek not to underplay the curiosity of the movement's dominant recapitulation or its exposition's atypical tonal plan, especially in sonata-theoretical terms, but rather to offer a reading which explores fully the significance of the fraught but productive dialogue between tonal and rhetorical (thematic, gestural and dynamic) components.

\section{46/i: Exposition, Analysis 1}

Fig. 1 presents a tonally orientated interpretation of the exposition of D. 46/i. As is clear, this reading outlines a somewhat atypical 'continuous exposition'.

Fig. 1 Schubert, String Quartet in C major, D. 46/i, exposition. Reading 1: continuous exposition

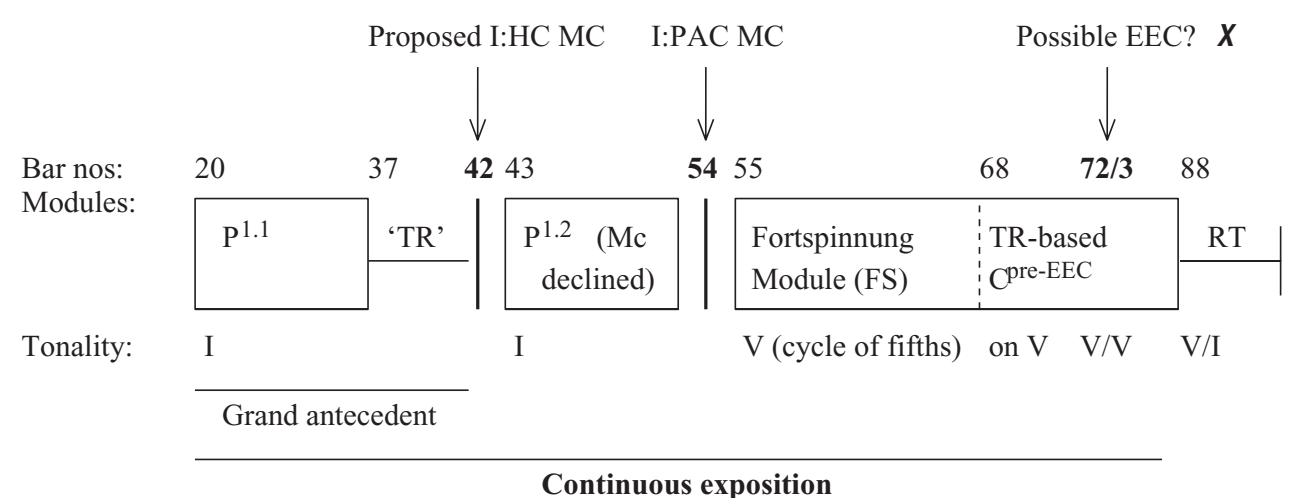


The 'grand antecedent' encompassing the first module of $\mathrm{P}$ and the transition (TR) is demarcated by a proposed half cadence in the tonic (I:HC) MC at bar $42 .{ }^{12}$ The use of this second-level default MC acts as an ominous indicator that the movement will prove not to be straightforward for sonata theory, since Hepokoski and Darcy state that the 'I:HC ... sometimes generates problems in what follows' (2006, p. 26). To be sure, this 'proposed MC' - the cadence reinforced as expected by a general pause (GP) immediately following in bar 42 - is retrospectively 'declined' (ibid., p. 45) by the ensuing music, which presents new thematic material yet remains in the tonic key. This thematic module is labelled $\mathrm{P}^{1.2}$ in Fig. 1 owing to its grounding in the tonic and thus its unsuitability as $\mathrm{S}$.

A second attempt at confirming an accepted MC is made at bars 54-55, but here again the (even lower) fourth-level default (a I:PAC) is problematic, and its inability to divide the exposition into a two-part form is reinforced by the repeated denial during the ensuing music of any appropriate $S$ theme in the dominant. The dynamics at this point reinforce the sense of struggle, because the weak MC is articulated at a hushed pianissimo, while the determined (although ultimately ineffectual) module at bar 55 enters forcefully at forte. Two specific features of the bars following this MC undermine their ability to produce the $S$ theme. First, the thematic material at bars 55-57 does not constitute a new theme in itself, nor is it a 'presentation phrase' of the kind outlined by Caplin. ${ }^{13}$ Rather, it consists of a one-bar fragment of $\mathrm{P}^{1.2}$, which is treated sequentially and, at bar 58, simultaneously juxtaposed with the initial four notes of the descending chromatic tetrachord figure (motive ' $y$ ') and the full figure from the adagio introduction (motive ' $x$ '; see Ex. 1). This profusion of motivic fragmentation and sequence is designated a Fortspinnung module (FS) in Fig. 1. Secondly, the primacy of the dominant key at the outset (in G major, the progression is $i \mathrm{i}-\mathrm{V}^{\frac{6}{3}}-\mathrm{I}$ ), soon gives way to a series of descending fifths beginning at bar 59 , the sequential nature of which is more closely related to development than to thematic statement.

By this relatively late stage in the exposition, we have perhaps relinquished any hope of an identifiable $S$ theme's being introduced and instead presume that the music will lead to the articulation of the EEC: a PAC in G major. ${ }^{14}$ This expectation is not fulfilled: despite the repeated V-I progression in bars 64-71, nowhere is there a perfect cadence with $\hat{1}$ in the top voice which would suitably provide the EEC. Bars 72-73 (Ex. 2) offer one possible candidate: after a two-bar standing on $\mathrm{V} / \mathrm{V}$, the bass drops down to $\mathrm{G}$ and the top voices reaches $\hat{1}$ of $G$, as required. The thematic material leading up to this cadence is, however, continuous and not cadential in function, and the ensuing music reveals no gestural signal of completion or closure. ${ }^{15}$ Because Hepokoski and Darcy define the EEC as the occurrence not merely of a PAC, but of one which 'proceeds onward to differing material' (2006, p. xxvi), this cadence cannot provide the conclusive moment. In fact, this cadence occurs during what I have labelled the TR-based closing zone $\left(\mathrm{C}^{\text {pre-EEC }}\right)$, which begins in bar 68 and involves 
Ex. 1 Schubert, String Quartet in C major, D. 46/i, bars 55-62
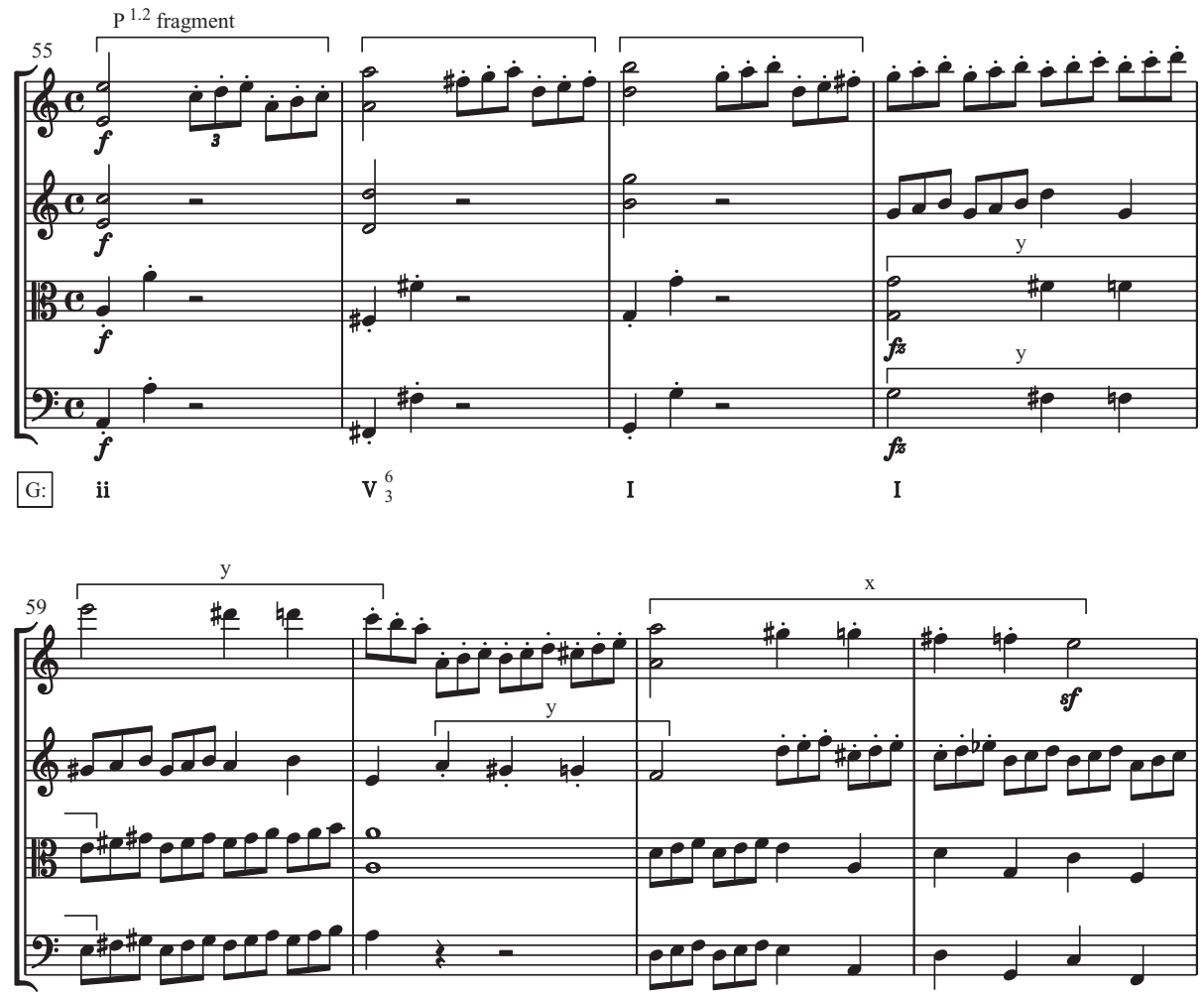

Ex. 2 Schubert, String Quartet in C major, D. 46/i, bars 71-73, possible EEC

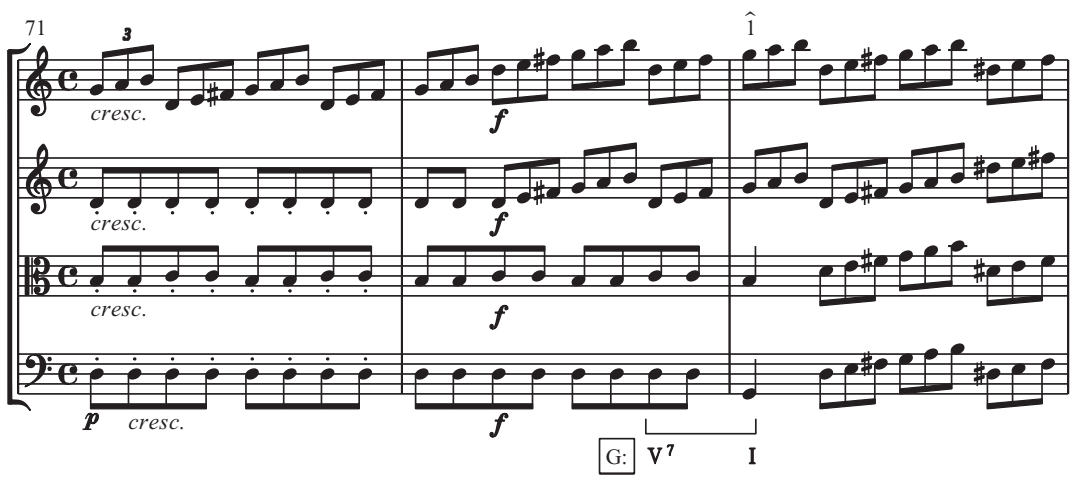


Ex. 3 Schubert, String Quartet in C major, D. 46/i, bars 37-42, TR material
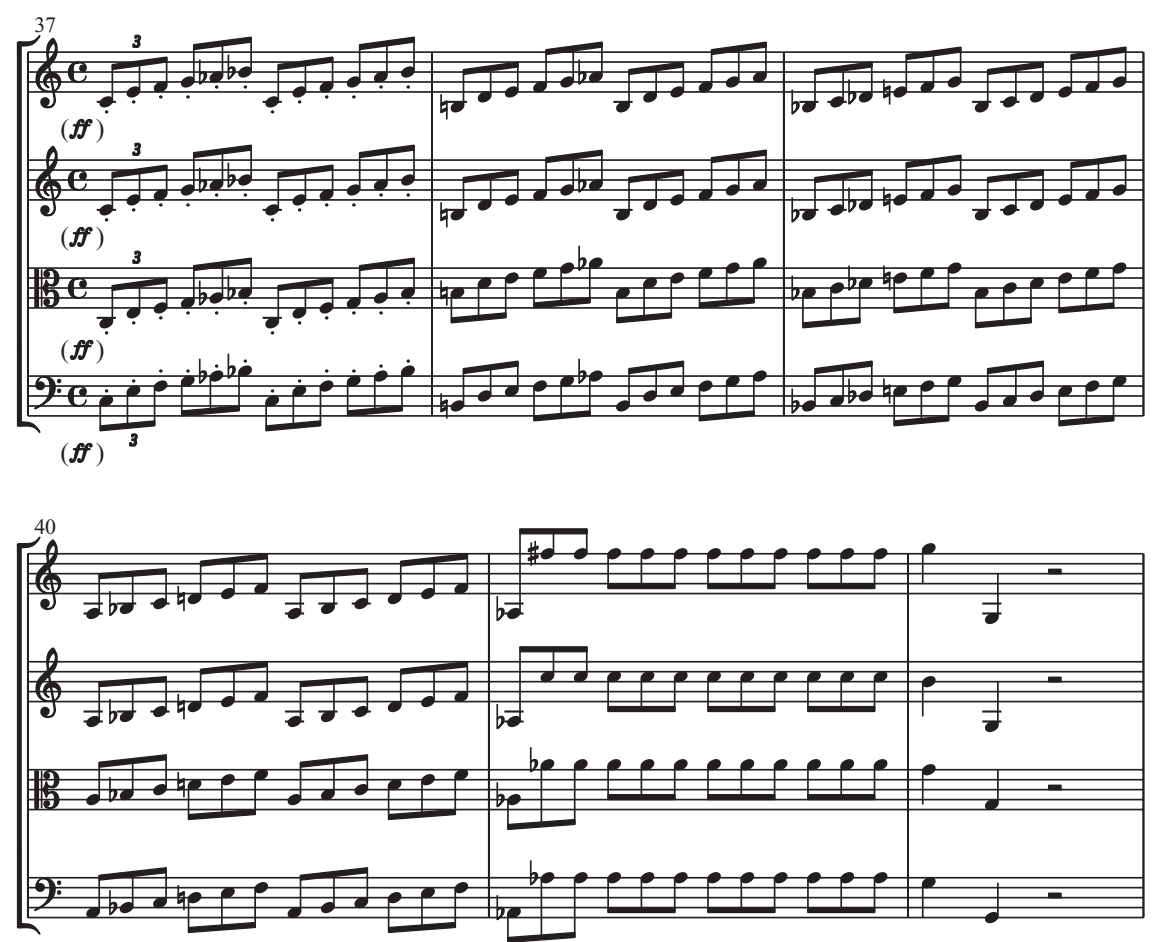

the liquidation of the $\mathrm{P}^{1.2}$ theme (bars 75-85) and the subsequent commencement of the retransition (RT), recalling the introductory theme, at bar 88. My identification of bars $68-87$ as $\mathrm{C}^{\text {pre-EEC }}$ is potentially problematic for sonata theory, but it hinges on the similarity between this music and that of the TR. In particular, the rhythmic similarity between bars 37-40 and 71-74 implies a similar formal function for these sections. This may be observed by comparing Ex. 2 with Ex. 3 below.

This interpretation of the exposition of D. 46/i produces two main analytical conclusions in relation to the form of the movement, which may be understood hermeneutically. First, as outlined above, the denial of the first MC is not redressed by the second proposed MC (an unexpected I:PAC), which also fails to summon the $S$ theme in the new key. This is problematic for sonata theory, because $S$ carries the burden of articulating expositional closure. ${ }^{16}$ Secondly, and more significant, the subsequent material fails to articulate a V:PAC and therefore does not provide the EEC, which would successfully close the expositional space. For sonata theory, this means that the status of bars $68-87$ as an independent section $\left(\mathrm{C}^{\text {pre-EEC }}\right)$ is uncertain, or at the least weaker than a more 'normative' C. This complete evasion of the point of essential closure also creates a sense of instability and openness within the exposition and raises the expectation that it will be resolved in the recapitulation. 


\section{46/i: Exposition, Analysis 2}

An alternative reading of the exposition, one which grants prominence to rhetorical (thematic and dynamic) elements above considerations of tonality, is offered in Fig. 2. As can be seen, the main point on which this analysis differs from the previous reading is its reinterpretation of $\mathrm{P}^{1.2}$ as a genuine $\mathrm{S}$ theme despite its tonic presentation, thus engendering a two-part rather than a 'continuous' exposition. ${ }^{17}$ The trimodular-block design of the exposition's second part is unorthodox in that it exhibits only $\mathrm{TM}^{1}$ and $\mathrm{TM}^{3}$ modules, with the more transitional $\mathrm{TM}^{2}$ omitted, possibly on account of the highly unusual I:PAC MC at bars $54-55 .{ }^{18}$ The result is an $S$ with two modules: $\mathrm{TM}^{1}$ and $\mathrm{TM}^{3}$. Within this two-part exposition, the $\mathrm{C}^{\text {pre-EEC }}$ from Fig. 1 is re-labelled $S^{c}$ owing to its presence as a closing theme now within $\mathrm{S}$ space.

Although certainly uncharacteristic, this reading is not without precedent in sonata theory. As mentioned in note 7, the first movement of Mozart's String Quintet in G minor, K. 516, exhibits a design similar to the one outlined here in that, according to Hepokoski and Darcy, the exposition's i:PAC MC fails to produce an $S$ theme which is capable of overcoming the (minor) tonality of the tonic. $\mathrm{S}$ is therefore presented initially in $\mathrm{G}$ minor (beginning with the upbeat to bar 30); only much later (in bar 64) does it resolutely establish the expected mediant major. Ex. 4 reproduces the $S$ theme. Hepokoski and Darcy interpret the $\mathrm{G}$ minor theme at bar 29 as the $S$ theme because 'the rhetorical signals make it clear that this is S' $(2006$, p. 29), thus allowing thematic and rhetorical material to act as the defining parameters. Taken as a whole, however, their reading of $\mathrm{K}$. 516 seems somewhat contrived. ${ }^{19}$ Particularly vexing is their interpretation of the repeat of $\mathrm{P}$ in the first viola part at bar 9 as the TR (of the dissolving-consequent type), which needlessly truncates $\mathrm{P}$ and retrospectively reinterprets the consequent phrase as the TR. There is no reason that P cannot be better understood as continuing until the PAC in G minor at bar 29, in which case the consequent phrase may be said to repeat and expand upon the antecedent. ${ }^{20}$ Sonata theory's

Fig. 2 Schubert, String Quartet in C major, D. 46/i, exposition. Reading 2: two-part exposition

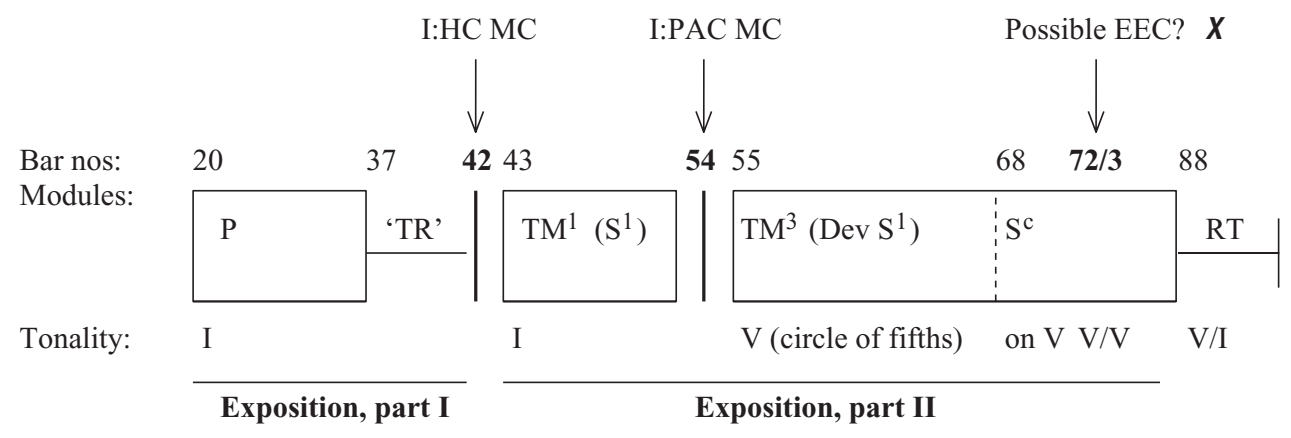


Ex. 4 Mozart, String Quintet in G minor, K. 516/i, bars 28-33, second subject opening
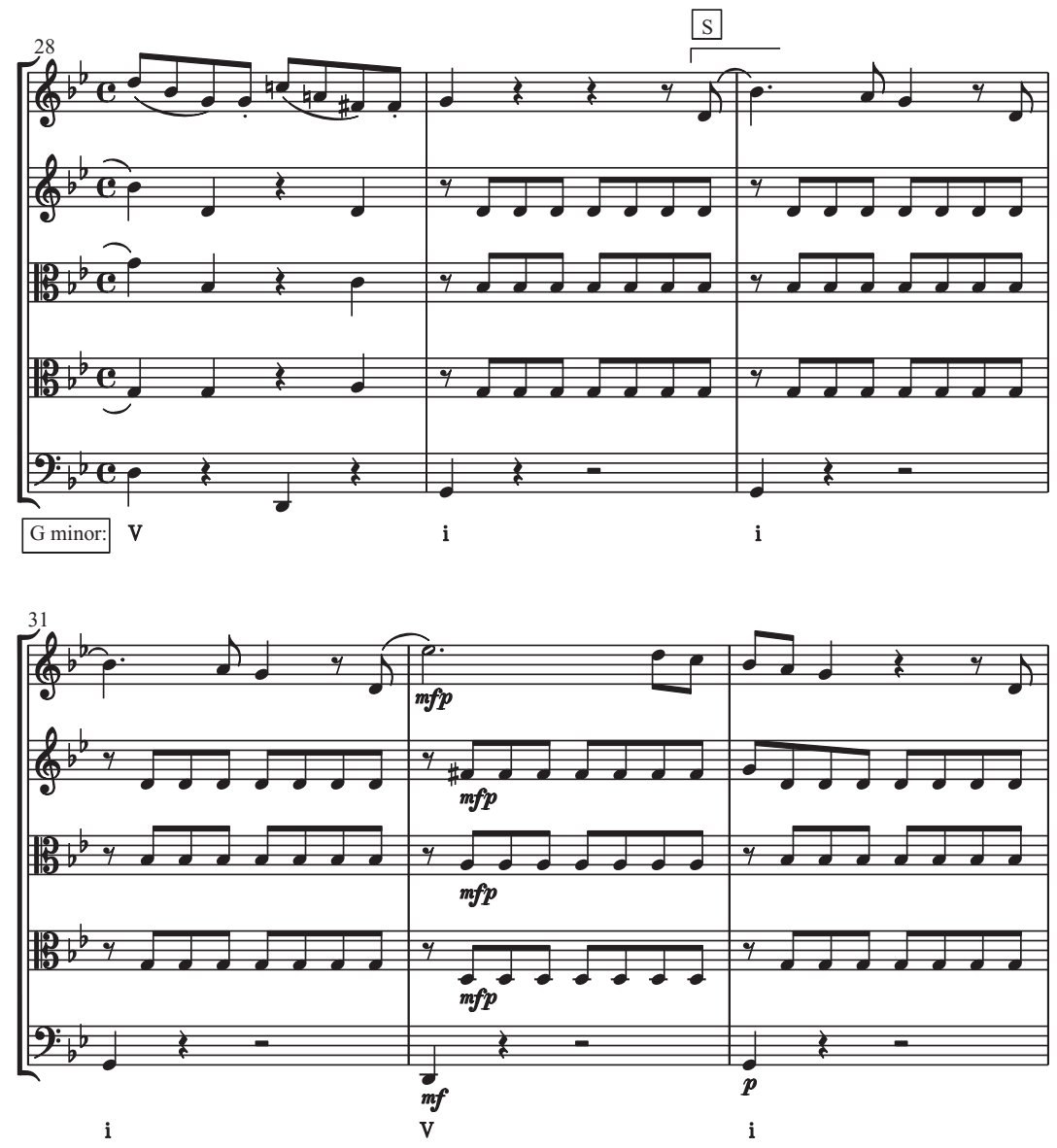

reading of K. 516 nonetheless offers a theoretical precedent for the design of D. 46/i's exposition, since the rhetorical signals here are equally strong and support a similar reading of $S$ in the tonic.

By momentarily placing thematic and dynamic signals above the tonal requirements of the form, this analysis suggests two complementary points of departure from sonata theory: first, that the prolongation of the tonic need not discount the commencement of S, since the rhetorical and thematic material supports this demarcation (a point conceded by sonata theory in relation to $\mathrm{K}$. 516); and secondly, by the same logic, that the absence of a PAC does not rule out the presence of a closing section, albeit within $S$ space $\left(\mathrm{S}^{\mathrm{c}}\right)$. In other words, although these sections are tonally elided, they are marked as discrete by the rhetorical and thematic gestures of closure and difference which separate them. 
Fig. 3 Schubert, String Quartet in C major, D. 46/i, tonal elision and rhetorical demarcation across the movement

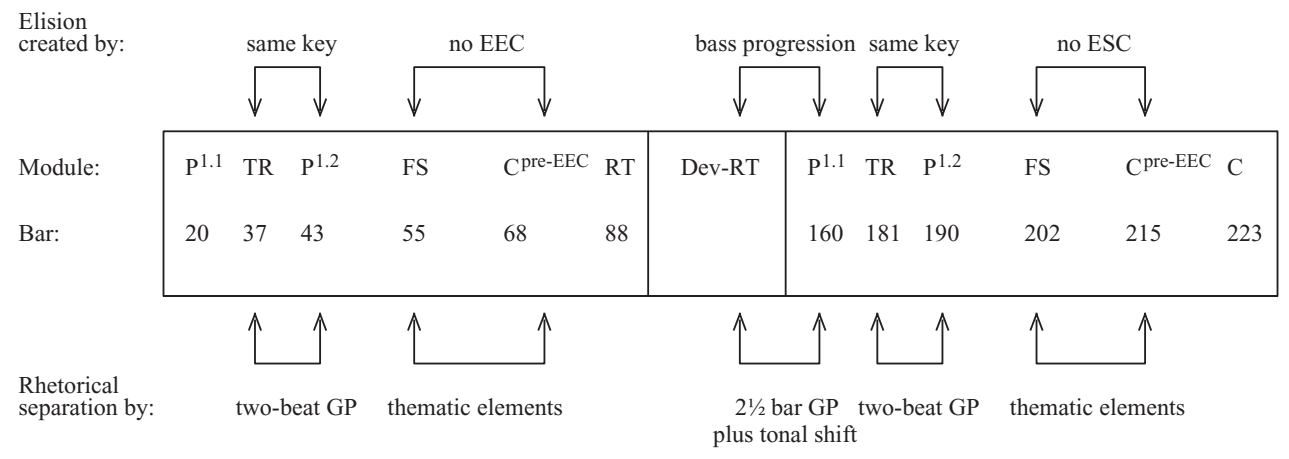

$(\mathrm{GP}=$ General Pause $)$

In this sense, the exposition can be explained as tonally through-composed or open ended (in that it lacks conclusive tonal closure), while also exhibiting a rhetorically segmented structure.

Taken individually, both of my interpretations of this exposition are unhelpfully myopic. The first analysis, championing tonality, is unsatisfactory and counter-intuitive in its conflation of sections which, from a rhetorical perspective, are clearly distinct. The second analysis, although it assigns significance to rhetorical and thematic features, is equally problematic in its submission that $S$ can be presented in the tonic key without ever modulating to the expected dominant, which surely contradicts the very definition of $S$ in an early nineteenth-century sonata. In short, the two readings exacerbate the tonal/ rhetorical polarisation of this exposition instead of accounting for its significance within the movement. As Peter Smith has suggested, 'Rather than become bogged down in a debate about the primary or secondary status of aspects of tonal form, we should be flexible enough in our analytic approach to view surface motivic processes and voice leading as two crucial components of an aggregate structure - the total musical fabric within which each dimension can be understood more fully' (1994, p. 240). This dissociation of tonal and rhetorical aspects is not confined to the exposition. Considering the movement as a whole, we discover that the denial of simultaneous parametric closure is in fact central to the 'compositional dynamic' of D. 46/i. ${ }^{21}$ Fig. 3 summarises the tonal elision of musical spaces and their simultaneous rhetorical demarcation. In short, the expositional TR and $\mathrm{P}^{1.2}$ are elided in that they are in the same key, and the same is true of these sections in the recapitulation. Also, the FS and $\mathrm{C}^{\text {pre-EEC }}$ expositional sections and their corresponding $\mathrm{P}^{1.3}$ and $\mathrm{C}^{\text {pre-ESC }}$ sections in the recapitulation possess no EEC or ESC which would divide them tonally. Lastly, the end of the development, RT and the recapitulation are clearly elided, as all three are firmly rooted on the dominant. The rhetorical demarcation of all of these musical 
spaces (either by the use of rests or by thematic mirroring) is evident on the lower level of Fig. 3.

It is therefore abundantly clear that a specifically tonal end orientation with a focus on the delineation of distinct formal spaces, such as that found in sonata theory, runs contrary to the thematic and rhetorical parameters of this movement, which avoids definite gestures of tonal closure. The key to interpreting such non-congruence, then, is not to assert the prominence of one parameter over another, but rather to take into account the manner in which the spaces of the sonata interact with and inform each other. To this end, the next section examines in detail the dominant orientation of this movement's recapitulation.

\section{46/i: Recapitulation}

The recapitulation of $\mathrm{D}$. 46/i, far from offering any immediate resolution (by being, for instance, tonally stable), instead continues the narrative of tonal elision and rhetorical demarcation with even wider-reaching structural repercussions. Fig. 4 plots the recapitulation's formal plan, following the tonally oriented graphology of Fig. 1. Schubert's choice of a ${ }_{4}^{6}$ tonic chord, with its dominantharmonic function, for a reprise of the opening material of the sonata space is ostensibly problematic because it thwarts the expectation of a double return of primary theme and tonic harmony. Indeed, it confuses the role of the dominant at this stage in the sonata, which is traditionally one of preparation and not restatement: 'Here again we find the splaying of two ideas normally kept separate - dominant preparation and thematic return - only in a more extreme format. Because such situations are exceptional to normative practice, we consider them to be recapitulatory deformations' (Hepokoski and Darcy 2006, p. 276).

The counter-argument that off-tonic reprises are not, in fact, exceptional to Schubert's normative practice requires but a passing mention; a thorough examination of Schubert's modes of recapitulation lies beyond the scope of this essay. ${ }^{22}$

Fig. 4 Schubert, String Quartet in C major, D. 46/i, recapitulation, continuous recapitulation reading

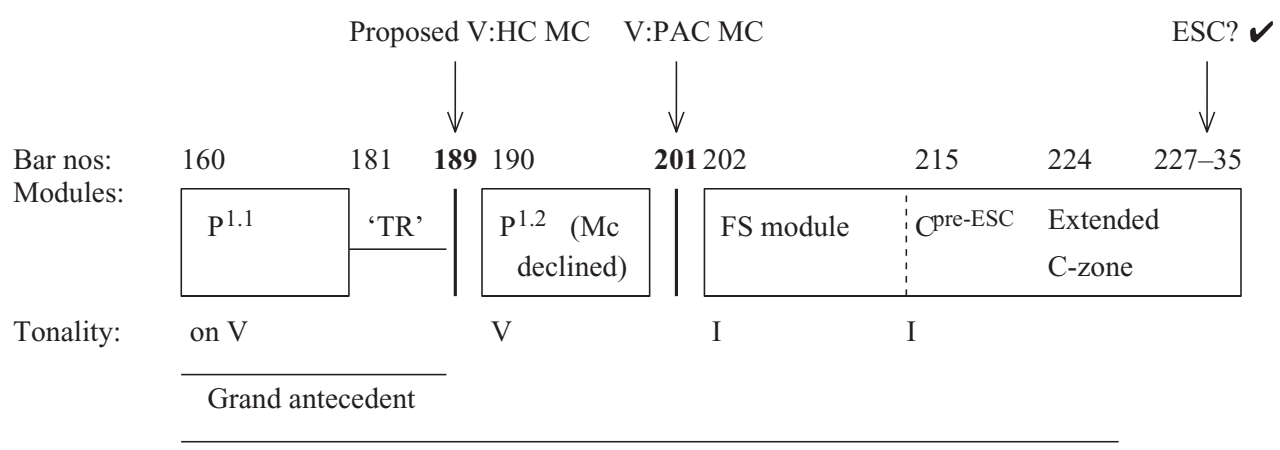

Continuous recapitulation 
Ex. 5 Schubert, String Quartet in C major, D. 46/i, bars 150-163, RT and beginning of recapitulation
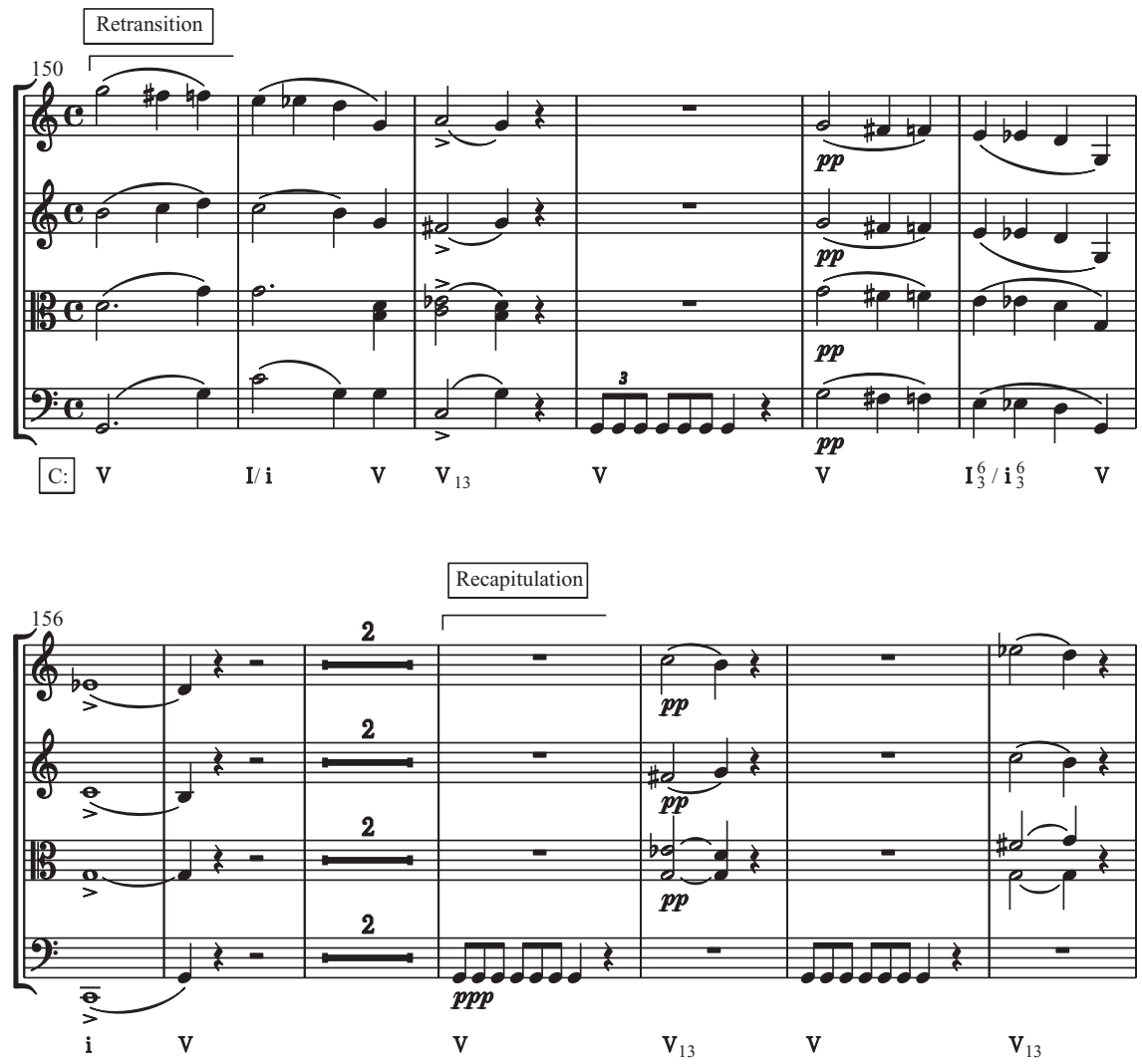

More pertinent is the notion that the recapitulation over an active ${ }_{4}^{6}$ chord results in the virtual spilling over of the preparatory dominant into and past the moment of thematic return, as in the first movement of Beethoven's 'Appassionata' Sonata, Op. 57. This creates a 'structural overlap' akin to that noted by Smith (1994, p. 238) in relation to Brahms's music. ${ }^{23}$ Although the practice is less well developed here, the comparison is nonetheless compelling.

As we might have anticipated, this tonal elision of RT and the restatement of $P$ are not reinforced rhetorically. In fact, our perception of RT and the recapitulation as two discrete sections is unproblematic owing to the two-and-a-half-bar silence which emphasises the sectional break (the score of RT and beginning of the recapitulation are reproduced in Ex. 5). The sheer length of this silence denies the rhetorical superimposition of the two sections on the musical surface and leaves us in no doubt as to where the recapitulation actually begins. It does not, however, eliminate the tonal elision at this point in the music, despite what Poundie Burstein has elsewhere called the effective 'closing off' (2005, p. 324) of RT's 
Ex. 6 Harmonic reduction of Schubert, String Quartet in C major, D. 46/i, bars 145-163

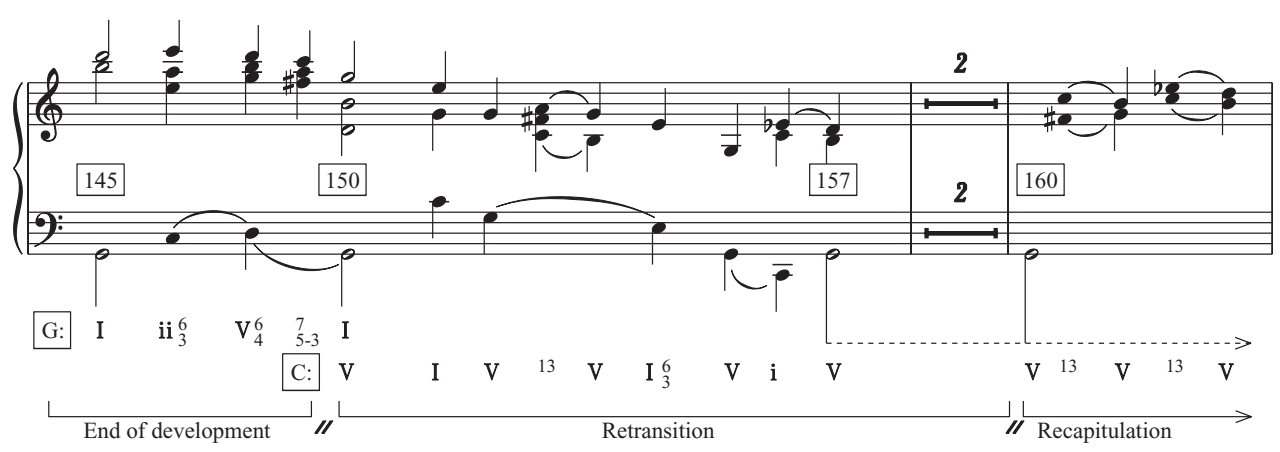

dominant chord from what follows by the use of a rhetorical silence. ${ }^{24}$ Appealing to rhetorical elements in this manner confuses a gap in the musical surface with a gesture of formal closure, since 'a break in rhythm and texture may occur at moments that are formally [i.e. harmonically] open' (Caplin 2004, p. 97).

The situation is further complicated by the consecutive rather than simultaneous arrival of the home tonality and its stabilisation within the bass progression. In other words, although the key of $\mathrm{C}$ has indeed returned by bar 160, it arrives before the bass has settled on I; as a result, the bass progression and tonal plot are out of synchronisation. Ex. 6 offers a reduction of the passage. Just as the presence of $\mathrm{S}$ was undermined by parametric non-congruence in the exposition, so too is the articulation of the moment of recapitulation - always a site of particular interest in a Schubertian sonata form - obscured by the continued conflict (or dialogue) of parameters, this time tonal plot and bass progression. The structural blurring which arises from these events affords the movement a sense of formal openness or, as suggested above, of through-composition, which delays ultimate closure. The appearance of $\mathrm{P}$ at bar 160 therefore constitutes a moment of return, although not one of resolution, a distinction which will be vital to our understanding of Schubert's procedure in D. 46/i.

There are two large-scale repercussions of this ${ }_{4}^{6}$ recapitulation for the movement as a whole. First, the dominant-weighted re-beginning may be understood as a balancing response to the prominence of the tonic in the exposition and, in particular, the tonic presentation of $\mathrm{P}^{1.2}$. The double appearance of thematic material $\left(\mathrm{P}^{1.1}\right.$ and $\mathrm{P}^{1.2}$ ) in $\mathrm{I}$ in the exposition renders a uniform recapitulation of material in I excessive, and thus the reprise of $\mathrm{P}^{1.1}$ over a ${ }_{4}^{6}$ and $\mathrm{P}^{1.2}$ in $\mathrm{V}$ in the recapitulation can justifiably be read as compensatory and restorative. In fact, because of the unusual tonal organisation of the exposition, there is no presentational passage articulated fully in the dominant. Schubert's response to this absence is to turn the sonata principle on its head by writing a tonally mobile recapitulation. ${ }^{25}$ If we view this movement as a reversal of the usual tonal function of the exposition and recapitulation, the recapitulation on $\mathrm{V}$ makes 
perfect sense as a generative and structurally aware response to the tonicoriented or tonic-heavy exposition. ${ }^{26}$ The tonic is therefore retrospectively rendered dissonant and 'requiring resolution', being counterbalanced in the same manner as an expositional dominant. ${ }^{27}$

Secondly, the effect of this large-scale tonal reversal and active bass progression is the denial of that sense of resolution which would usually occur at the moment of a double return. Despite the clear thematic return, the articulation of the tonic is postponed until the movement's tonal drama has been evened out or redressed. Schubert initiates the harmonic progression of the recapitulation in an unexpected place so as to lead to and ultimately end up in the tonic, thus shifting the moment of resolution to a later point in the movement. This notion of progression, rather than tonic arrival, as resolution creates a sense of delayed closure, which reveals a decidedly end-oriented or teleological mentality. In this respect, D. 46/i represents an early example of the practice of tonic deferral, which became a staple of Schubert's own sonata practice and part of the massive expansion of the Beethovenian coda (Marston 2000b). Gordon Sly, in particular, has devoted much analytical attention to Schubert's off-tonic recapitulations in the instrumental music. He remarks that

\begin{abstract}
Schubert indulged his penchant for beginning the thematic return away from the tonic in sonatas composed throughout his career - from those written as a young teenager, to the framing movements of the $\mathrm{B}$, Piano Trio and the finale of the Great C-major Symphony, both conceived in the last years of his life. His wellknown propensity for preserving in the recapitulation the broad modulation scheme of the exposition underlies many of these designs, such that the tonic serves as goal, rather than as source, of the tonal motion. (2001, p. 120)
\end{abstract}

To be sure, D.46/i also has historical significance beyond Schubert's own corpus of works. The strategy at work in this movement can be seen as relating back to the first movement of Beethoven's 'Appassionata' Sonata, Op. 57, as noted above, and pointing forward to the Finale of Mendelssohn's Fantasy for piano ('Scottish Sonata'); the first movement of his Fourth Symphony ('Italian'), Op. 90; and the first movements of Schumann's Third Symphony ('Rhenish'), Op. 97, Dvořák's Fifth Symphony and Tchaikovsky's First and Fourth Symphonies, the recapitulations of which all commence over a dominant-functioning 6 chord. The nineteenth-century tendency towards downplaying the moment of double return has been noted by Charles Rosen: 'The generation born around 1810 preferred to place the climax, the point of extreme tension, very near the end of the work ... . What they reject, in most cases, is the sense of climax and resolution at the end of the development and the beginning of the recapitulation' (Rosen 1988, p. 393). Indeed, this practice was pushed even further in the music of later nineteenth-century composers, where the moment of resolution is withheld across the individual movements of a multi-movement work until the Finale. ${ }^{28}$ In D. 46/i, Schubert is still working, as did Brahms later, 'thoroughly within the sonata style' (Smith 1994, p. 238), although he reorientates classical 
sonata form in order to accommodate a more progressive historical mindset one of progression as resolution.

This interpretation of the form of D. 46/i as a large-scale progression towards a state of closure (and thus resolution) differs markedly from the more normative 'fixed' sonata-theoretical formal mould. The merit of my approach lies in the structural import it affords to the persistent non-congruence of tonal and rhetorical domains throughout the movement. As I suggest below, it also permits the analytical incorporation of the ubiquitous chromatic motive ' $x$ '.

\section{46/i: The Role of the Introduction}

In the Fourth Quartet ... the chromaticism of the introductory Adagio is important. A certain blurring effect which it creates serves to make the contours of the structure vague rather than definite and tends to modify and alter the 'classical' order of the themes. New significance is attached to parts of the structure which previously had no more than a transitional or episodic function. The introduction, the end of the exposition and similar sections take on fresh meaning. In the present instance the chromaticism of the introduction (with a literal quotation of its theme) recurs during the second half of the exposition where the second theme 'ought' to appear. (Vetter 1953, pp. 164-5, trans. Lichtenfeld 1999, p. 10, cited in Black 1997, pp. 131-2) $)^{29}$

Walther Vetter's contention that the presence of the introductory theme (motive ' $x$ ') at bar 43 effectively undermines the appearance of $S$ is of utmost significance to the current analysis, revealing a direct correspondence between the slow introduction and the interior of the sonata. The inability of the music to modulate to the expected dominant at this point - even though new thematic material is obviously presented - may in fact be understood as a consequence of the introduction's continued presence in the sonata. Ex. 7 reproduces the slow introduction and labels the descending chromatic tetrachord motive ' $x$ '. This motive is not only topically significant, engendering the fundamental motivic and affective material for the remainder of the movement, but also plays out a dramatic narrative of chromaticism versus diatonicism, which is related to the postponement of closure. Furthermore, as Vetter suggests, this blurring of the movement's sectional boundaries grants a new significance to 'parts of the structure which previously had no more than a transitional or episodic function'; RT is obviously a case in point. The simultaneous unfolding of this motivic narrative and the movement's goal-directed tonal process - and their mutual dependence - engenders a conflict which is spun out and resolved only at the movement's end.

In this respect, D. 46/i differs substantially from its most apposite precedent, Mozart's renowned 'Dissonance' Quartet in C major, K. 465, completed and published in $1785 .{ }^{30}$ Notwithstanding the clear parallel between Mozart's and Schubert's use of a heavily chromatic slow introduction preceding a sonata movement in $\mathrm{C}$ major, the manner in which these two introductions function 
Ex. 7 Schubert, String Quartet in C major, D. 46/i, bars 1-19, slow introduction showing the descending chromatic tetrachord, motive ' $x$ '
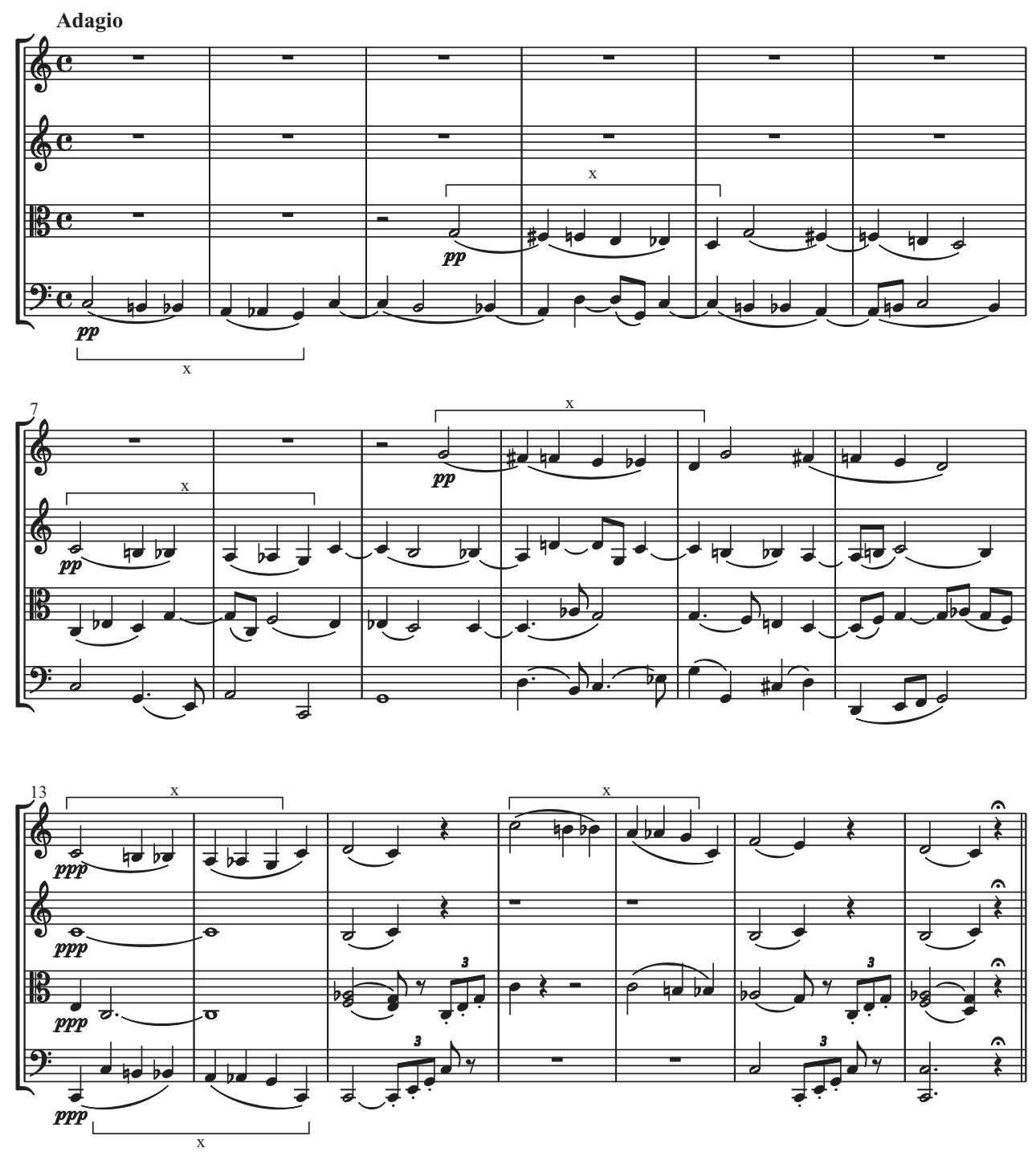

within their respective movements is significantly different. Once the exposition of Mozart's K. 465 commences, all vestiges of the chromatic opening dissipate, and a clear $\mathrm{C}$ major breaks through with confidence and stability. The primary theme of the exposition is therefore untainted by the chromaticism of the opening; its diatonicism is, as Thomas F. Dunhill memorably put it, 'plain sailing after what has gone before' (Dunhill 1927, p. 18). In direct contrast, allusions to motive ' $\mathrm{x}$ ' proliferate in the interior of $\mathrm{D} .46 / \mathrm{i}$, and the necessity for $\mathrm{C}$ major to 
Ex. 8 Schubert, String Quartet in C major, D. 46/i, bars 43-45 showing motive ' $x$ '

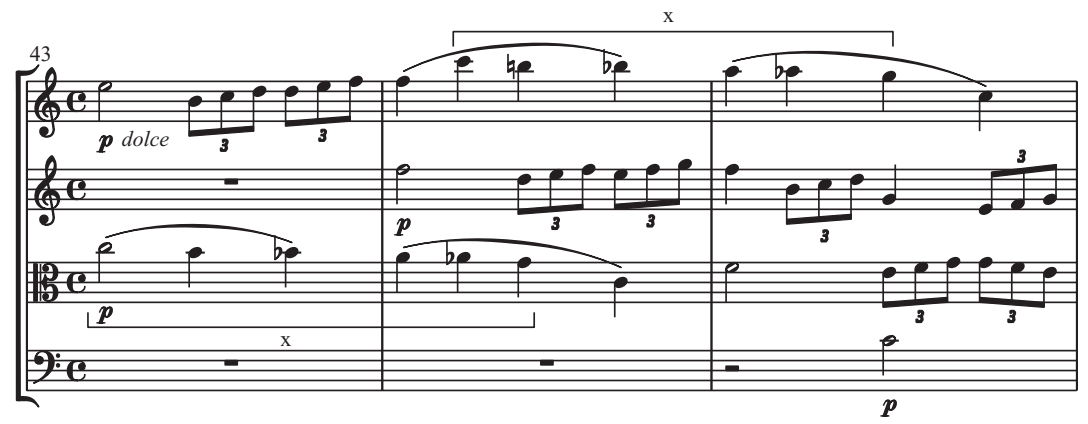

be resolutely affirmed later in the movement may thus be understood as a consequence of this pervasive chromaticism.

The extent to which this motive saturates the thematic material is indicative of its structural role. The $\mathrm{P}$ theme, for instance, is made up of a combination of motivic fragments from the introduction - namely motive ' $x$ ', which forms the chromatic dyads of the descending 'sigh' motive, and the pairs of consecutive triplets, introduced in bars 15 and 18. The descending chromatic tetrachord recurs at bars 37-40, where it is outlined in full by the first note of each bar of TR (see again Ex. 3). The new thematic material at bar 42, although sounding more major than that which preceded it owing to its cadential close in bar 48, is nonetheless replete with references to motive ' $x$ ' both in its melodic line, where it is registrally highlighted, and, in counterpoint against this, in the viola part, as shown in Ex. 8. The sequential treatment of this theme from bar 55 onwards abandons the full tetrachord almost entirely (save for bars 61-62) but retains a four-note fragment of it (motive ' $y$ ') in bars 58-59 in the lower two parts, bars 59-60 in the top part, bars 60-61 with the rhythm slightly altered and finally in bars $64-67$ in all parts except the bass. It is not until the closing theme commences, at bar 68, that motive ' $x$ ' and its association with the lament topic of the introduction is dispelled, offering a moment of relief. Furthermore, motive ' $x$ ' is here replaced with its inversion (a diatonic ascending fourth), labelled motive ' $z$ ', which Su Yin Mak has described as 'an antithetical variant of the lament bass' (2008, p. 150). This sequence is shown in Ex. 9. These rising diatonic fourth are rhetorically significant, representing, if you will, the utopian 'other' of the chromaticism which has hitherto dominated the movement, being ubiquitous in both of the main sonata themes.

The narrative is not complete, however, and the closing material reverts to repeated iterations of the chromatic dyads of $\mathrm{P}$ before RT begins after two bars of expectant silence, with repeated statements of the complete phrase which ended the introduction, now beginning on the fifth degree (see Ex. 10). This motivic plot emphasises the potential of the closing section to act as a moment 
Ex. 9 Schubert, String Quartet in C major, D. 46/i, bars 58-69 showing motives 'y' and ' $z$ '
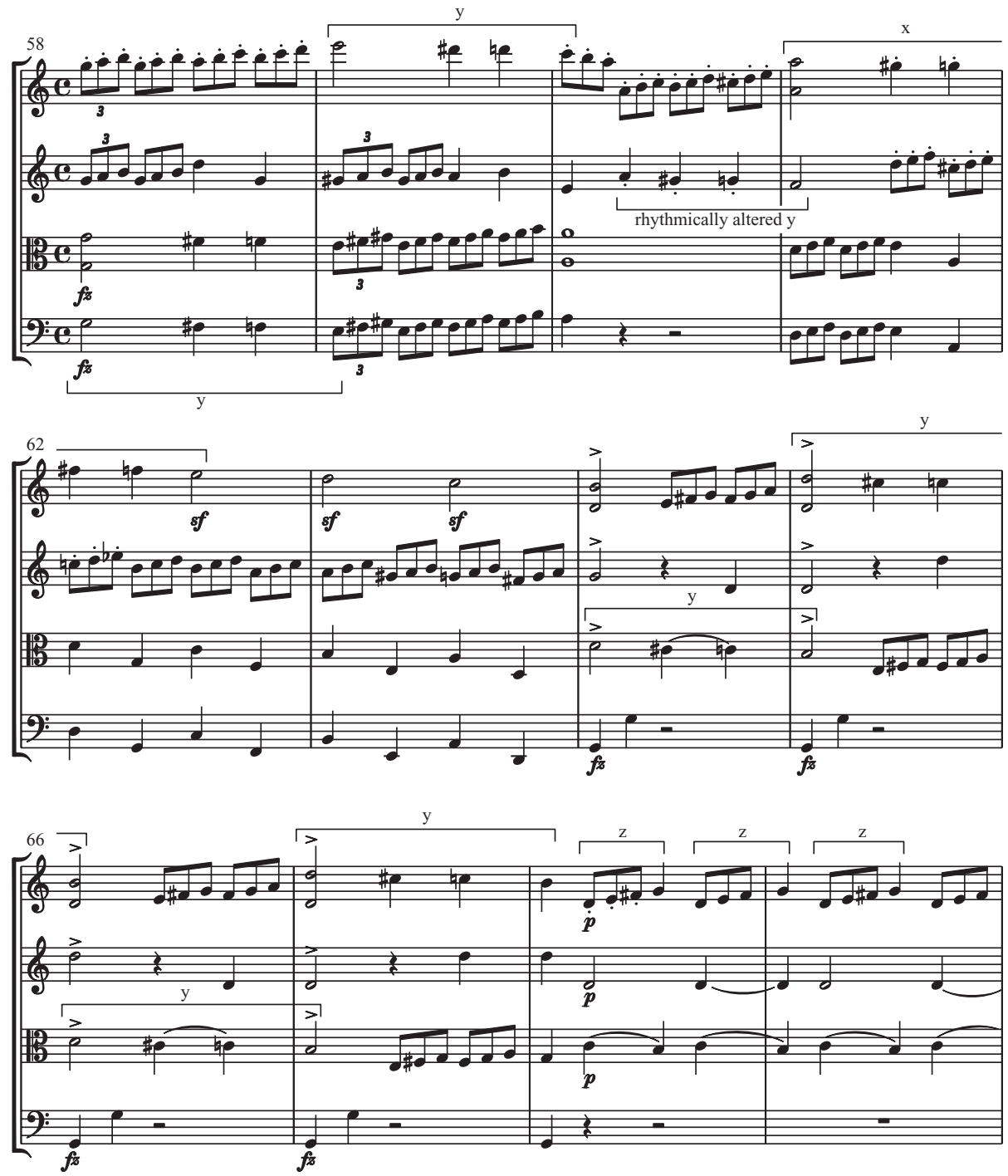

of resolution, which, although unsustainable in the exposition, may provide the apotheosis of the movement in the recapitulation.

My reading of the recapitulation above was concerned only with the ramifications of the dominant restart. The remainder of the recapitulation follows the outline of the exposition, save for the insertion of new bars at bars 185-187, leading to the first proposed $\mathrm{MC}-\mathrm{a} \mathrm{V:HC}$ in $\mathrm{G}$ major. The passage which follows $\left(\mathrm{P}^{1.2}\right)$ is the first thematic module in the movement to be articulated fully 
Ex. 10 Schubert, String Quartet in C major, D. 46/i, bars 75-94 showing chromatic dyads
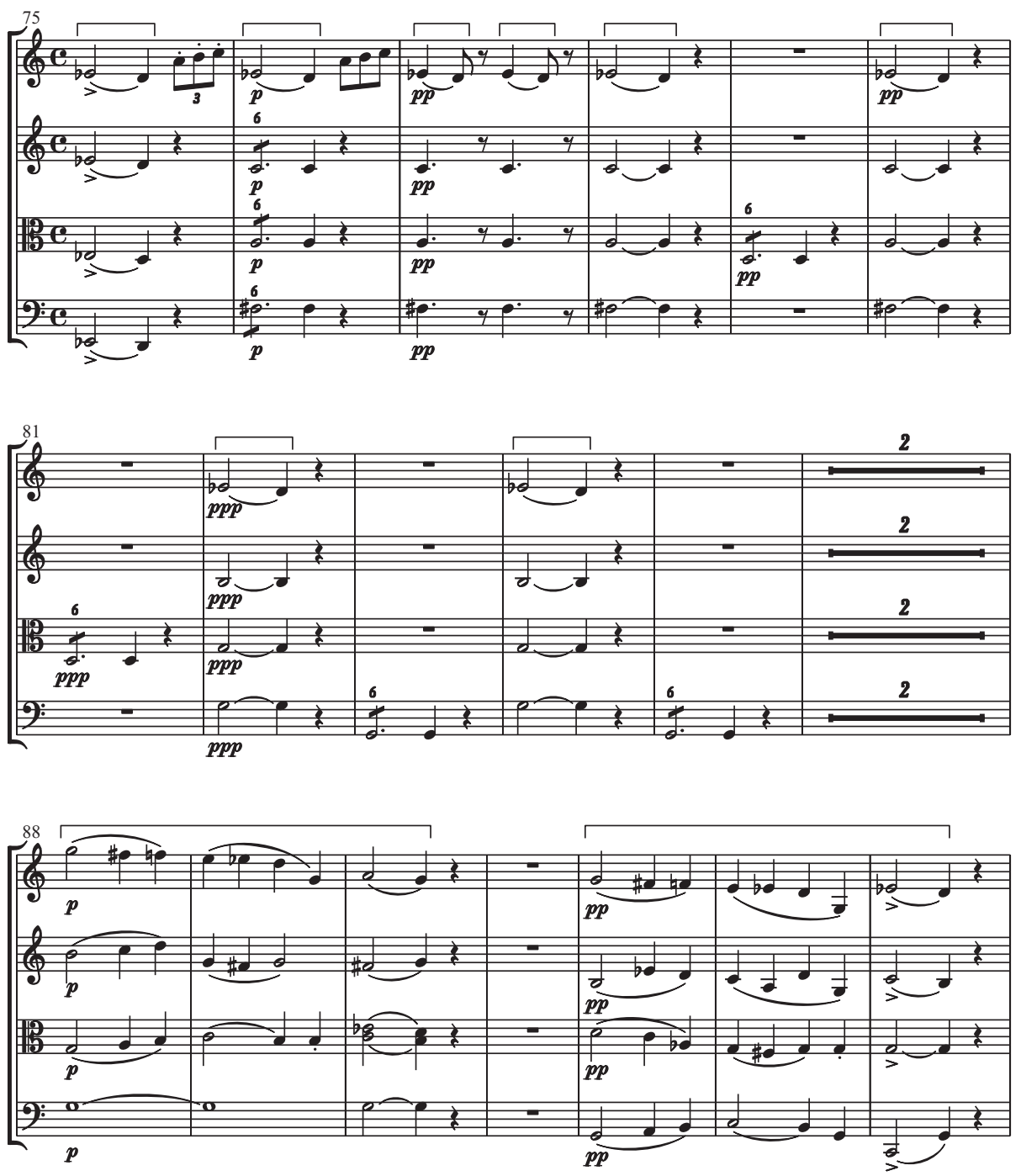

in the dominant, despite the obvious dominant orientation of the recapitulation up to this point. The tonal shift at bar 202 (now to $\mathrm{C}$ major) is made more secure by the substitution of the exposition's harmonic progression of $i \mathrm{i}-\mathrm{V}^{6}-\mathrm{I}$ (in G major) with the more stable I-IV-V-I in C major, although the presence of a $\mathrm{B} b$ in bar 202 retains the plagal cast of the opening module and the reiteration of motive ' $y$ ' in the viola and cello at bars 205-206 preserves the harmony's chromatic inflection. 
Ex. 11 Schubert, String Quartet in C major, D. 46/i, bars 224-235 showing motive ' $x$ '
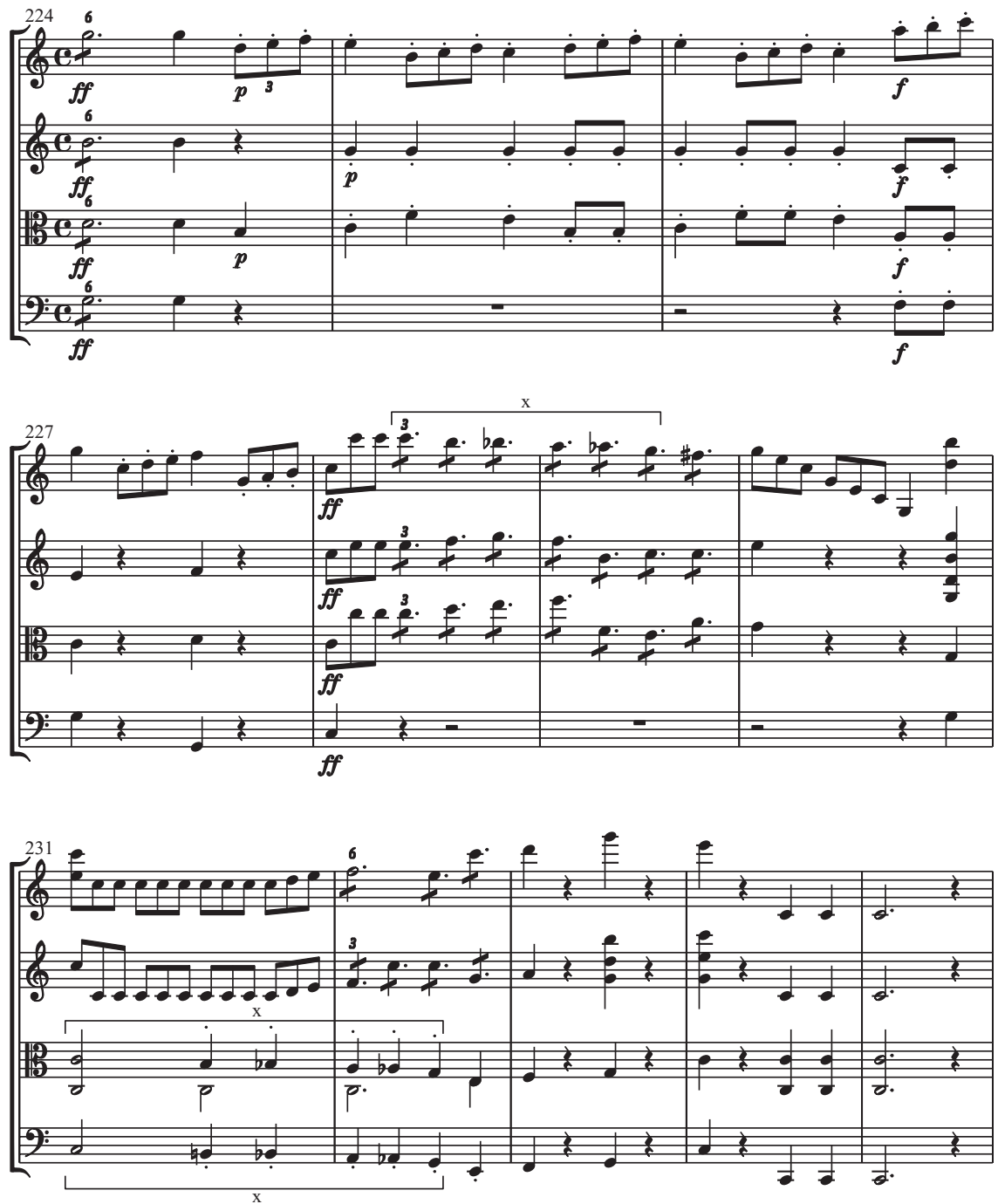

The final bars of music deliver the desired resolution by simultaneously providing closure in the form of a PAC and, more important, by incorporating the chromatic motive ' $x$ ' into the diatonic cadence, thus dispelling the tension generated by this chromatic presence. As can be seen in Ex. 11, beginning at bar 224, the music drives towards the first of two PACs in C major. Both are frustrated, however, and lack any true sense of cadential relaxation or finality on account of their constant movement and registral disquiet. They are also infused 
with the chromaticism of motive ' $x$ ', appearing first in the top voice (bars 228-229) and subsequently in octaves in the viola and cello parts at bars 231-232. This vestige of the dissonant introduction's tonal ambiguity does not, however, undermine the thrust towards a final affirmation of tonic harmony, but rather foregrounds Schubert's bold juxtaposition of full restatements of motive ' $x$ ' with repeated perfect cadences in the home tonic. To argue that the final cadence - an IAC with $\hat{1}$ articulated only as a registrally displaced cadential addendum - brings to the movement a conclusive sense of finality (with its implied hammer blows on $\hat{1}$ ) seems an inevitable and pedestrian observation. What is significant about these final bars is not that $\mathrm{C}$ major is affirmed as the tonal goal of the work - which was hardly ever in question - but that the repeated tendency of $\hat{1}$ to fall chromatically to $\hat{5}$ which was initiated in the slow introduction and maintained throughout the movement is incorporated into a series of diatonic cadences.

The idea of a meaningful correlation between the movement's opening chromaticism and its subsequent aberrant tonal plan is particularly compelling when we bear in mind Schubert's propensity for creating correspondences between what we might term the 'micro' and 'macro' elements of formal design. The structural merits of this procedure are outlined by Sly:

[A] salient feature of the movement's opening music ... prepares the choice of tonal level for its recapitulation. These opening features, then, act essentially as motives, and will be considered as such here, though they depart from the more usual sense of the term as referring to a simple melodic shape or span. Their emergence as foundational within the broad tonal architecture of these movements illuminates a depth and elegance of conception not widely ascribed to Schubert as a composer of sonatas. (Sly 2001, p.121)

Although D. 46/i does not present the more developed procedure of tonicising the pitches of the descending chromatic tetrachord across the large scale (such as he does in the Quartettsatz of 1820), the primary motive of the slow introduction nevertheless proves fundamental to the work's tonal plan. ${ }^{31}$ This practice is mirrored by another distinctive characteristic of Schubert's instrumental style, in which structural oppositions are made apparent on the surface in the final bars of music, highlighting not only the significance of such conflicts, but also the weight and import of their resolution for the movement's formal design. A similar design is evident in the first movement of the Quartettsatz, where the densely chromatic opening bars are recapitulated at the very end, incorporating the fortissimo bII ( $\left.\begin{array}{c}6 \\ 3\end{array}\right)$ Neapolitan chord from the movement's opening into the final cadence. Neapolitan and third relations have significant structural import in this movement; the foregrounding of a remnant of the work's tonal conflict at such a late stage is made even more striking when it is adjusted to proceed to a perfect authentic cadence, as shown in Ex. 12. This practice reaches its pinnacle, of course, in the final two notes of the String Quintet in C major, in which the Neapolitan relationships that inform the 
Ex. 12 Schubert, Quartettsatz in C minor, D. 703/i, bars 305-315
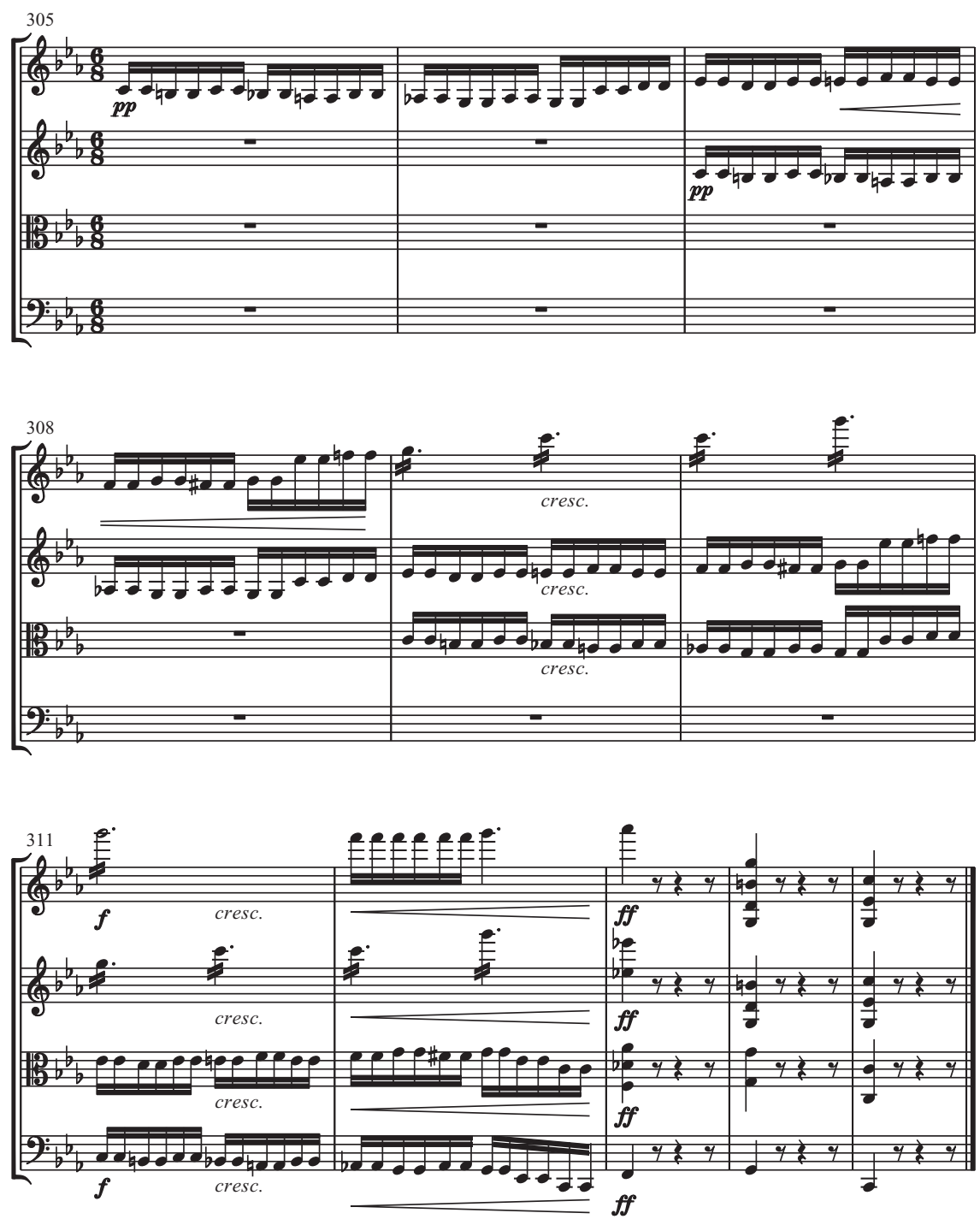

entire work are again clearly foregrounded - this time as part of the Finale's ultimate cadence.

In D. 46/i, the formal indispensability of the introduction's chromatic motive to the sonata suggests that it ought not to be relegated to the position of a 'parageneric space'. Such formal alienation of the introduction is not justified in this movement, given that the opening nineteen-bar adagio does more than set up, for instance, 'the negative (minor-mode) state of affairs or situation to overcome' or provide 'the source-material for much of what follows' (Hepokoski 
Ex. 13 Heinrich Schenker's musical example of the 'auxiliary cadence' from Der freie Satz

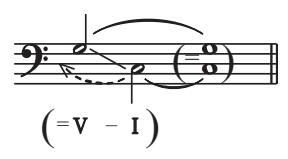

and Darcy 2006, pp. 301-3). To be sure, this introduction can be understood as fulfilling both of these roles; confining our interpretation of its function to such categories, however, ignores its greater significance within the sonata.

\section{Conclusions}

The interpretation of D. 46/i presented here relies on the premise that the persistent non-congruence of tonal and rhetorical parameters results in the subversion of local closure, such that any sense of resolution is postponed until the tonal/rhetorical conflict has been played out. Essential to this reading is an understanding of the dominant recapitulation as a distinctly end-oriented or teleological device, replacing tonic arrival as resolution with progression towards the tonic goal as resolution. The role played by the introduction's chromatic motive ' $x$ ' in the tonal/rhetorical drama and in maintaining a sense of tonal openness (or unfulfilment) throughout the movement also begs for the integration of this traditionally discrete section with the interior of the sonata.

The uninterrupted structure suggested by the amalgamation of these elements has significant theoretical consequences. First, it is problematic for the Schenkerian definition of sonata form as an interrupted two-part voice-leading structure. The moment of double return in particular is imperative to Schenker's definition of sonata form. When the tonic is denied at the moment of thematic return, the harmony, according to his concept of the auxiliary cadence, is understood to point towards or set up the impending root of the tonic chord. In Der freie Satz, Schenker writes that 'the territory of the previous harmony [the ${ }_{4}^{6}$ progression] provides a base for the preparation of the following one [the tonic]' (1979, p. 88). His accompanying musical example is reproduced in Ex. 13. Following Schenker's example, then, the late affirmation of tonic harmony in the recapitulation of $\mathrm{D}$. 46/i means that all of the recapitulatory material before bar 202 ought to be understood, in retrospect, as part of an auxiliary cadence to I. However, this reading would critically underplay the formal role of the dominant at the moment of return, which is one of tonic deferral rather than tonic preparation, and is therefore not helpful to an interpretation of this movement. Indeed, the insistence on a divided voice-leading structure for D. $46 / \mathrm{i}$ seems to reinforce Sly's claim that it is 'at best ... an awkward fit; at worst, a distortion' (2001, p. 122). It seems more appropriate, 
then, to understand this movement as exhibiting an undivided structure, in line with Mak's analysis:

Schubert's key plan, according to which I(i)-I-V in the Exposition is answered by $\mathrm{V}(\mathrm{v})-\mathrm{V}-\mathrm{I}$ in the Recapitulation, suggests a continuous voice-leading structure that parallels the rhetorical progress of the movement ... . Unlike the typical sonata form, then, there is no interruption in the structural descent of the fundamental line. (Mak 1997, p. 161)

Secondly, the almost complete negation of local cadential resolution reinforces an interpretation of this movement as an instance of global closure. This challenges sonata theory's fundamental principle of punctuation, for it suggests that tonal closure does not guarantee spatial definition - or, to put it differently, that cadential closure of one section is not necessary for the commencement of the next rhetorical sonata space. If this is the case, and the spaces of a sonata can follow one another without requiring closure in the form of a cadence, then the essential nature of both the EEC and the ESC is debatable. Certainly, in a movement such as D. 46/i, where tonal closure is persistently evaded and boundaries between the various sonata spaces are elided by means of a continuing bass progression, we can justifiably question the assumption, implicit in sonata theory, that if structural cadences are avoided or somehow frustrated, the teleological trajectory of the work is automatically impeded. Indeed, as was demonstrated, the deferral of tonal closure is not detrimental to the ongoing, dynamic nature of this work but may in fact be understood as a dynamic, form-generating force in itself.

These analytical conclusions highlight the limitations of a strictly hierarchical approach to formal design, in which rhetorical elements are, to recall AnsonCartwright, 'neglected or subordinated to tonal factors'. They also point to the historical boundaries of sonata theory, which, despite being expressly concerned with sonata form of the late eighteenth century, has been instructive in the analysis of much later music as well in its employment of the concepts of deformation and dialogue. ${ }^{32}$ Its emphasis on punctuation, however, is here revealed as historically quite limited, already disintegrating under the procedures of an early nineteenth-century movement. The theory is therefore methodologically precarious outside of a very narrow historical sphere.

D.46/i demonstrates the need to adopt a less Procrustean approach to analysis, particularly in instances of extensive parametric non-congruence. Sonata theory's confinement of temporal processes within a predominantly spatial conception of form therefore cannot represent the fluidity of a dialogue which is inherently more than a simple case of the temporal being 'housed' within the spatial. A more inclusive model of formal closure, such as I have adopted here, which is alert not only to the breadth of various parameters of closure, but also to their interaction and, most important, to instances of their non-congruence, is therefore methodologically preferable. Such an approach may help us better understand the intrinsically permeable relationship between the temporal and spatial aspects of the Schubertian musical landscape. 


\section{NOTES}

Initial research for this article was made possible by a travel grant from King's College, Cambridge to attend the Sixth European Music Analysis Conference in Freiburg im Breisgau in October 2007, and I am very grateful for this support. To James Hepokoski, Julian Horton, Nicholas Marston and James Webster I also extend sincere thanks for their expert guidance and insightful comments on this work during its incipient stages as a conference paper.

1. An extensive use of metaphors of musical space is evident in the fournal of Music Theory, 42/ii (1998), which is devoted entirely to a study of neo-Riemannian theory and its application.

2. A vast corpus of literature has been generated on this topic. For a representative cross-section from musical, literary and philosophical texts see Joan Stambaugh, 'Music as a Temporal Form', fournal of Philosophy, 61/ix (1964), pp. 265-80; Patricia Carpenter, 'Musical Form Regained', fournal of Philosophy, 62/ii (1965), pp. 36-48; Zofia Lissa, 'The Temporal Nature of a Musical Work', fournal of Aesthetics and Art Criticism, 26/iv (1968), pp. 529-38; Mitchell (1980); Morgan (1980); Naomi Cumming, 'Metaphors of Space and Motion in the Linear Analysis of Melody', Miscellanea musicologica, 17 (1990), pp. 143-66; Robert Adlington, 'Musical Temporality: Perspectives from Adorno and de Man', Repercussions, 6/i (1997), pp. 5-60; Spitzer (2003); Adlington, 'Moving beyond Motion: Metaphors for Changing Sound', Fournal of the Royal Musical Association, 128/ii (2003), pp. 297-318; and Max Paddison, 'Performance, Reification, and Score: the Dialectics of Spatialization and Temporality in the Experience of Music', Musicae Scientiae, Forum de Discussion 3 (2004), pp. 157-79.

3. It seems rather odd, given this fact, that the term teleology does not appear anywhere in the authors' otherwise exhaustive index of concepts.

4. For comprehensive appraisals of the application of sonata theory in practice, see Spitzer (2007), Riley (2008), Whittall (2008) and Wingfield (2008).

5. The concept of parametric non-congruence, which is a fundamental component of my argument, stems from James Webster's concept of multivalence and will be discussed in greater detail in the body of this essay. For expositional texts on multivalent analysis see Webster (1991 and 1992). Examples of the application of multivalence in the analysis of first-movement sonata form can be found in Webster (2009).

6. The distinctly tonal orientation of the MC is also clear from the authors' shorthand; for instance, the I:HC MC.

7. For a particularly illuminating review of the rotational principle, see Wingfield (2008), especially pp. 149-53. My observations on the nature of D. 46/i in relation to this principle offer further analytical support for Wingfield's remarks.

8. The sole exception to this rule is sonata theory's reading of Mozart's String Quintet in G minor, K. 516. In this, the authors place rhetorical considerations above tonal concerns and allow for the identification of $S$ in the tonic. See Hepokoski and Darcy (2006, p. 29). I shall return to a more detailed account of this movement later in the present article. 
9. As such, my analysis applies sonata theory to a work which lies slightly outside of its historical remit, but is sufficiently close in type to classical sonata form to merit consideration in this manner.

10. The first movement of Schubert's String Quartet in D major, D. 74, also possesses a dominant recapitulation; however, since this is a Type 1 sonata (i.e. with no development section), it is best interpreted as a large-scale binary form, in which the structure of the recapitulation mirrors that of the exposition. A comparison between D. $46 / \mathrm{i}$ and the first movement of the Fourth Symphony, D. 417, is equally misleading. Although both display Type 3 characteristics and regain the tonic only at a very late moment in the recapitulation, the recapitulation of D. 417 begins in the dominant minor and thus in $\mathrm{v}$ rather than on $\mathrm{V}$. For sonata theory's analysis of the first movement of Schubert's Fourth Symphony, see Hepokoski and Darcy (2006, pp. 277-8).

11. It is worth emphasising here that Schubert was just sixteen when he composed this Quartet, and thus issues of artistic maturity and aesthetic integrity should be taken into account when discussing its 'non-normative' or aberrant features.

12. The term grand antecedent refers to 'a lengthy, multimodular antecedent idea that constitutes the first extended limb of P' (Hepokoski and Darcy 2006, pp. 45-6). Schubert ultimately 'declines' this gambit in a manner similar to that outlined by Hepokoski and Darcy for the Finale of Beethoven's Second Symphony.

13. William Caplin defines the function of the presentation phrase as creating 'a solid structural beginning for the theme by establishing its melodic-motivic content in a stable harmonic-tonal environment' (1998, p. 35).

14. For the various ways in which the articulation of $\mathrm{S}$ can be bypassed in an exposition, see Hepokoski and Darcy (2006, pp. 53-60).

15. William Caplin's useful distinction between cadential arrival and cadential function is instructive to this reading of bars 72-73. Caplin argues that 'the phenomenon of cadence as closure consists of more than just the moment of cadential arrival, for there must be some musical material immediately preceding that arrival whose formal purpose is to announce "a cadence is forthcoming"' (Caplin 2004, p. 77). Although the point at which the cadential dominant falls to the tonic in bar 73 may be understood as the moment of cadential arrival, the lack of any anticipatory musical material in the lead-up to this undermines the sense of closure it can achieve.

16. In the locus classicus of the 'MC declined' offered by Hepokoski and Darcy, mentioned in note 12 above - the Finale of Beethoven's Second Symphony - the second MC, a V:HC, leads unproblematically to a new lyrical theme in the dominant, and through this attains expositional closure. On this, see Hepokoski and Darcy (2006, pp. 45-6).

17. An interesting feature of the exposition to this point strengthens this reading. The plagal, $\mathrm{F}$ major character of $\mathrm{P}$ sets up the $\mathrm{C}$ major tonality of this theme in bar 43 as a kind of pseudo-dominant, thereby reinforcing its (local) case to be heard as $\mathrm{S}$.

18. The term trimodular block refers to 'an especially emphatic type of multimodular structure in an exposition or recapitulation, always associated with the phenomenon of apparent double medial caesuras. Individual modules may be designated as $\mathrm{TM}^{1}$, $\mathrm{TM}^{2}$, and $\mathrm{TM}^{3}$. Of these, $\mathrm{TM}^{1}$ and $\mathrm{TM}^{3}$ are usually "thematic" (Hepokoski and 
Darcy 2006, p. xxvii). A more conventional application of sonata theory would not support my identification of a trimodular block in this analysis since, for one thing, $\mathrm{TM}^{1}$ does not occur in $\mathrm{G}$ major. The lack of any $\mathrm{TM}^{2}$ is similarly unusual, although it may be explained as a result of the I:PAC MC in bars 54-55, the strength of which, the authors suggest, often results in 'the effective ellipsis of TR' (Hepokoski and Darcy 2006, p. 29).

19. The fact that this movement has previously been understood in terms of concerto ritornello form complicates its applicability as a precedent for D. 46/i.

20. This is also the conclusion reached by Wingfield (2008, p. 167) regarding sonata theory's analysis of K.516/i.

21. David Epstein defines the 'compositional dynamic' as 'the inner energies and action of a work - the drives, themes, tensions integral to its materials (its psyche, so to speak)'. See Epstein (1979, p. 198).

22. Daniel Coren's 1974 article remains the most comprehensive account of Schubert's methods of recapitulation across his instrumental output. Coren calculates that only 47 (or just over 62 per cent) of Schubert's 75 sonata-form movements include 'normative' tonic recapitulations, whereas the remaining 28 (almost 38 per cent) are off-tonic. Although Coren's observations are certainly revealing, his conclusion that 'sonata form for Schubert, before 1820, was a thematically stable and unambiguous structure' (Coren 1974, p. 573) does little justice to the large-scale tonal plots which underline some of these off-tonic recapitulations. More detailed investigations of particular movements may be found in Beach (1993), Marston (2000a) and Sly (2001).

23. Despite the applicability of the term structural overlap to D. $46 /$ i, we must be mindful to distinguish Schubert's blurring of the RT and recapitulation in this movement from the Brahmsian practice outlined by Smith of 'extend[ing] developmental activity' (Smith 1994, p. 237) into the return of the main theme in the recapitulation. In Brahms' recapitulatory overlaps the return of $\mathrm{P}$ 'simultaneously continues the developmental process of augmentation and initiates the recapitulation' (ibid., p. 238) resulting in ambiguity at the point of return, whereas in D. 46/i, developmental activity ceases and the 'overlap' is caused by the bass progression on $\mathrm{V}$, which continues between the sections.

24. Burstein offers a converse reading of the fourth movement of Haydn's String Quartet in A major, Op. 55 No. 1, in which he argues that 'the pronounced pause which precedes the return of the main theme [on V] strongly suggests that the cadential V chord is closed off from what follows' (2005, pp. 324-5). Burstein's submission, however, that in a dominant reprise 'the texture or thematic design help to determine whether the $\mathrm{V}$ of the imperfect cadence should be regarded as closed off' (ibid. p. 324) needlessly simplifies the significance of the tonal overlap, which may have large-scale repercussions for the movement in toto.

25. Charles Rosen outlines the sonata principle as 'all the material played in the dominant is consequently conceived as dissonant, ie, requiring resolution by a later transposition to the tonic' (1988, p. 25). For a consideration of the 'sonata principle' in relation to sonata theory, see Hepokoski and Darcy (2006, pp. 242-5).

26. The same strategy of balancing a tonally static exposition with a tonally mobile recapitulation is in evidence across several of Chopin's early compositions in sonata 
form. The first movements of the Piano Sonata in C minor, Op. 4, the Piano Trio in $\mathrm{G}$ minor, Op. 8 and the Concerto No. 1 in E minor, Op. 11 are just three examples. Since I have just invoked Rosen's concept of the sonata principle, it is interesting to cite his acerbic disparagement of Chopin's C minor Piano Sonata: 'The exposition of the Sonata in C minor, op. 4, of 1827 never leaves the tonic. Chopin was only sixteen when he wrote it, but it is not the kind of mistake that Mozart would have made when he was six. They evidently did not have very clear ideas about sonatas out there in Warsaw' (Rosen 1988, p. 392, n. 3). Rosen's implication is that Chopin's sonatas became more 'orthodox' (ibid., p. 392) once he left Poland.

27. The more normative concept of the sonata principle also obtains in this movement, where the second half of the exposition is repeated in the home tonic.

28. For an example of this practice from the repertoire, see especially Bruckner's Fifth Symphony.

29. 'Für das vierte Quartett, C-dur (1813), ist die Chromatik des einleitenden Adagio wichtig. In sich von einer gewissen, mehr der Auflösung als der Festigung der Konturen dienenden Unschärfe, fördert sie die Verlagerung und Umschichtung der klassischen Themenordnung. Das Schwergewicht der musikalischen Vorgänge wird in Partien verlegt, die einstmals über vermittelnde oder episodische Bedeutung nicht hinausgingen. Einleitung, Expositionsschluß und ähnliche Teile gewinnen neue Bedeutung. Im vorliegenden Falle taucht die Chromatik der Einleitung (unter tongetreuer Zitierung ihres Themas) in der zweiten Hälfte der Exposition auf, wo eigentlich das zweite Thema seinen Platz hätte' (Vetter 1953, pp. 164-5).

30. The opening of Mozart's Fantasia in C minor, K. 475, again dating from 1785, is a further example of a chromatic beginning, although the generic difference makes it less suitable for comparison with D. 46/i.

31. Su Yin Mak (1997 and 2008) has explored Schubert's use of the descending tetrachord in the large-scale structure of the Quartettsatz, D.703.

32. I am thinking in particular of James Hepokoski's pioneering work on the music of Jean Sibelius (1993).

\section{REFERENCES}

Adorno, Theodor W., 1928: 'Schubert', Die Musik, 21, pp. 1-12, trans. Jonathan Dunsby and Beate Perry, 19th-Century Music, 29/i (2005), pp. 3-15.

Agawu, Victor Kofi, 1982: 'The Structural Highpoint as Determinant of Form in Nineteenth-Century Music' (PhD diss., Stanford University).

Agawu, V. Kofi, 1984: 'Structural "Highpoints" in Schumann's "Dichterliebe", Music Analysis, 3/ii, pp. 159-80.

, 1987: 'Concepts of Closure and Chopin's Opus 28', Music Theory Spectrum, 9, pp. 1-17.

, 1991: Playing with Signs: a Semiotic Interpretation of Classic Music (Princeton, NJ: Princeton University Press).

Anson-Cartwright, Mark, 2007: 'Concepts of Closure in Tonal Music: a Critical Study', Theory and Practice, 32, pp. 1-18. 
Beach, David, 1993: 'Schubert's Experiments with Sonata Form: Formal-Tonal Design versus Underlying Structure', Music Theory Spectrum, 15/i, pp. 1-18. Black, Brian, 1997: 'Schubert's Apprenticeship in Sonata Form: the Early String Quartets' (PhD diss., McGill University).

Burstein, L. Poundie, 2005: 'The Off-Tonic Return in Beethoven's Piano Concerto No. 4 in G Major, Op. 58, and Other Works', Music Analysis, 24/iii, pp. 305-47.

Caplin, William E., 1998: Classical Form: a Theory of Formal Functions for the Instrumental Music of Haydn, Mozart, and Beethoven (New York: Oxford University Press). , 2004: 'The Classical Cadence: Conceptions and Misconceptions', Fournal of the American Musicological Society, 57/i, pp. 51-117.

Coren, Daniel, 1974: 'Ambiguity in Schubert's Recapitulations', Musical Quarterly, 60/iv, pp. 568-82.

Dunhill, Thomas F., 1927: Mozart's String Quartets, Book II (London: Oxford University Press, Humphrey Milford).

Epstein, David, 1979: Beyond Orpheus: Studies in Musical Structure (Cambridge, MA: MIT Press).

Hepokoski, James, 1993: Sibelius: Symphony No. 5 (Cambridge: Cambridge University Press). , and Darcy, Warren, 2006: Elements of Sonata Theory: Norms, Types, and Deformations in the Late-Eighteenth-Century Sonata (New York: Oxford University Press).

Johnson, Mark L., and Larson, Steve, 2003: "'Something in the Way She Moves" - Metaphors of Musical Motion', Metaphor and Symbol, 18/ii, pp. 63-84.

Lichtenfeld, Monika, 1999: 'A Documentation: Dates, Facts, Testimonies', trans. John Coombs in booklet for Schubert: Die Streichquartette, Melos Quartett Stuttgart, 6 CDs (Deutsche Grammophon), pp. 1-21.

Mak, Su Yin, 1997: 'Structure, Design, and Rhetoric: Variation Procedures in Selected Instrumental and Vocal Works by Franz Schubert' (PhD diss., Eastman School of Music).

, 2008: 'Et in Arcadia ego: the Elegiac Structure of Schubert's Quartettsatz in C Minor (D.703)', in Barbara M. Reul and Lorraine Byrne Bodley (eds.), The Unknown Schubert (Aldershot: Ashgate), pp. 145-56.

Marston, Nicholas, 2000a: 'Schubert's Homecoming', Fournal of the Royal Musical Association, 125/ii, pp. 248-70.

, 2000b: " "The Sense of an Ending": Goal-Directedness in Beethoven's

Music', in Glenn Stanley (ed.), The Cambridge Companion to Beethoven (Cambridge: Cambridge University Press), pp. 84-101.

Mitchell, W. J. T., 1980: 'Spatial Form in Literature: Toward a General Theory', Critical Inquiry, 6/iii, pp. 539-67.

Morgan, Robert P., 1980: 'Musical Time/Musical Space', Critical Inquiry, 6/iii, pp. 527-38.

Riley, Matthew, 2008: 'Sonata Principles', Music and Letters, 89/iv, pp. 590-8. 
Rosen, Charles, 1988: Sonata Forms, rev. ed. (New York: Norton).

Schenker, Heinrich, 1979: Free Composition, trans. and ed. Ernst Oster (New York: Longman).

Sly, Gordon, 2001: 'Schubert's Innovations in Sonata Form: Compositional Logic and Structural Interpretation', Fournal of Music Theory, 45/i, pp. 11950.

Smith, Peter, 1994: 'Liquidation, Augmentation, and Brahms's Recapitulatory Overlaps', 19th-Century Music, 17/iii, pp. 237-61.

Spitzer, Michael, 2003: 'The Metaphor of Musical Space', Musicae Scientiae, 7/i, pp. 101-20. , 2007: 'Sonata Dialogues', Beethoven Forum, 14/ii, pp. 150-78.

Webster, James, 1991: 'The Analysis of Mozart's Arias', in Cliff Eisen (ed.), Mozart Studies (Oxford: Clarendon Press), pp. 101-99.

, 1992: 'The Form in the Finale of Beethoven's Ninth Symphony', Beethoven Forum, I, pp. 25-62.

2009: 'Formenlehre in Theory and Practice', in Pieter Bergé (ed.), Musical Form, Forms and Formen lehre: Three Methodological Reflections (Leuven: Leuven University Press), pp. 123-39.

Whittall, Arnold, 2008: 'Representing Sonatas', Fournal of the Royal Musical Association, 133/ii, pp. 318-33.

Wingfield, Paul, 2008: 'Beyond "Norms and Deformations": Towards a Theory of Sonata Form as Reception History', Music Analysis, 27/i, pp. 137-77.

Vetter, Walther, 1953: Der klassiker Schubert, 2 vols. (Leipzig: Deutscher Verlag für Musik).

\begin{abstract}
This article addresses the issue of parametric non-congruence as it affects the articulation of closure in the first movement of Schubert's String Quartet in C major, D. 46. This movement displays two formal irregularities which render it problematic in relation to sonata theory: first, the presentation of new thematic material in the exposition does not correspond with a modulation to the dominant key, and second, the recapitulation of the primary theme commences over an active ${ }_{4}^{6}$ bass progression. As such, D. 46/i provides an apt setting for an appraisal of how effective sonata theory is in the treatment and understanding of closure when the very elements which ought to express it are ostensibly incompatible. The distinction I draw between tonal (syntactic) and rhetorical (semantic) closure in this article (founded in the work of Kofi Agawu, among others) aims at demonstrating that the adherence to a hierarchical perspective of form in which tonality dominates is of little service when examining a work in which local cadential closure is persistently evaded. Ultimately, my analysis shall illustrate the through-composed design of this movement and, in so doing, question the unrelenting reliance on cadence and contrapuntal closure as delineators of sonata space.
\end{abstract}


Copyright of Music Analysis is the property of Wiley-Blackwell and its content may not be copied or emailed to multiple sites or posted to a listserv without the copyright holder's express written permission. However, users may print, download, or email articles for individual use. 